ARTICLE

Received 12 Nov 2015 | Accepted 26 Jul 2016 | Published 1 Sep 2016

DOI: $10.1038 /$ ncomms12702

OPEN

\title{
ORP4L is essential for T-cell acute lymphoblastic leukemia cell survival
}

Wenbin Zhong ${ }^{1}$, Qing $\mathrm{Yi}^{2}$, Bing $\mathrm{Xu}^{3}$, Shiqian $\mathrm{Li}^{1}$, Tong Wang ${ }^{1}$, Fupei Liu', Biying Zhu1, Peter R. Hoffmann ${ }^{4}$, Guangju $\mathrm{Ji}^{5}$, Pingsheng Lei ${ }^{6}$, Guoping $\mathrm{Li}^{7}$, Jiwei $\mathrm{Li}^{1}$, Jian $\mathrm{Li}^{7}$, Vesa M. Olkkonen ${ }^{8} \&$ Daoguang Yan $^{1}$

Metabolic pathways are reprogrammed in cancer to support cell survival. Here, we report that T-cell acute lymphoblastic leukemia (T-ALL) cells are characterized by increased oxidative phosphorylation and robust ATP production. We demonstrate that ORP4L is expressed in T-ALL but not normal T-cells and its abundance is proportional to cellular ATP. ORP4L acts as an adaptor/scaffold assembling CD3 $\varepsilon, G \alpha_{\mathrm{q} / 11}$ and PLC $\beta 3$ into a complex that activates PLC $\beta 3$. PLC $\beta 3$ catalyzes $\mathrm{IP}_{3}$ production in T-ALL as opposed to PLC $\gamma 1$ in normal T-cells. Up-regulation of ORP4L thus results in a switch in the enzyme responsible for $\mathrm{IP}_{3}$-induced endoplasmic reticulum $\mathrm{Ca}^{2+}$ release and oxidative phosphorylation. ORP4L knockdown results in suboptimal bioenergetics, cell death and abrogation of T-ALL engraftment in vivo. In summary, we uncovered a signalling pathway operating specifically in T-ALL cells in which ORP4L mediates $G$ protein-coupled ligand-induced PLC $\beta 3$ activation, resulting in an increase of mitochondrial respiration for cell survival. Targeting ORP4L might represent a promising approach for T-ALL treatment.

\footnotetext{
${ }^{1}$ Key Laboratory of Functional Protein Research of Guangdong Higher Education Institutes, Department of Biotechnology, College of Life Science and Technology, Jinan University, Guangzhou 510632, China. ${ }^{2}$ Department of Cancer Biology, Lerner Research Institute, Cleveland Clinic, Cleveland, Ohio 44195, USA. ${ }^{3}$ Department of Hematology, Nanfang Hospital, Southern Medical University, Guangzhou 510515, China. ${ }^{4}$ Department of Cell and Molecular Biology, John A. Burns School of Medicine, University of Hawaii, Honolulu, Hawaii 96813, USA. ${ }^{5}$ National Laboratory of Biomacromolecules, Institute of Biophysics, Chinese Academy of Sciences, Beijing 100101, China. ${ }^{6}$ State Key Laboratory of Bioactive Substances and Functions of Natural Medicines, Chinese Academy of Medical Sciences, Beijing 100050, China. ${ }^{7}$ The Key Laboratory of Geriatrics, Beijing Hospital, National Center of Gerontology \& Beijing Institute of Geriatrics, Ministry of Health, Beijing 100730, China. ${ }^{8}$ Minerva Foundation Institute for Medical Research, Biomedicum 2U, Helsinki FI-00290, Finland. Correspondence and requests for materials should be addressed to D.Y. (email: tydg@jnu.edu.cn).
} 
$\mathrm{R}$ eprogramming of metabolic pathways by oncogenic signalling has emerged as a hallmark of cancer cells and may offer attractive targets for anticancer strategies ${ }^{1-3}$. T-cell acute lymphoblastic leukemia (T-ALL) is one of the deadliest and most aggressive hematological malignancies. Despite progress in intensive chemotherapy has achieved a 5 -year event-free survival rate of $60-70 \%$ in children and $30-40 \%$ in adults, the success of the treatment is limited with $20-25 \%$ of paediatric and over $50 \%$ of adult patients with T-ALL exhibiting resistance to therapy and relapse ${ }^{4,5}$. Enhanced molecular understanding of T-ALL biology will ultimately facilitate a targeted therapy driven approach that can improve survival of refractory T-ALL patients.

$\mathrm{Ca}^{2+}$ released from the endoplasmic reticulum (ER) is taken up by mitochondria through the mitochondrial $\mathrm{Ca}^{2}+$ uniporter $(\mathrm{MCU})^{6-8}$. This process provides reducing equivalents to support oxidative phosphorylation ${ }^{9,10}$ through the activation of three intramitochondrial dehydrogenase ${ }^{10,11}$ and ATP synthase ${ }^{12}$.

Phospholipase Cs (PLCs) are a class of enzymes that execute an initial step in intracellular $\mathrm{Ca}^{2+}$ signaling ${ }^{13,14}$. In normal T-cells, PLC $\gamma 1$ is a dominant enzyme controlling $\mathrm{IP}_{3}$ production and $\mathrm{Ca}^{2}+$ homeostasis ${ }^{15}$. PLC $\gamma 1$ is activated through the TCR complex independent of $\mathrm{G}$ protein transduction. In contrast, anti-CD3-induced $\mathrm{Ca}^{2}+$ release was not impaired in T-ALL cells lacking PLC $\gamma 1$ (ref. 16), suggesting that other components beyond PLC $\gamma 1$ may be responsible for $\mathrm{Ca}^{2}+$ release in these cells. PLC $\beta$ s are canonical downstream targets of the Gq subfamily of $G$ protein-coupled receptors (GPCRs) and have been reported to regulate $\mathrm{Ca}^{2}+$ release upon anti-CD3 stimulation in Jurkat T-cells ${ }^{16}$. This raises the issue of the role that PLC $\beta$ s versus PLC $\gamma 1$ play in $\mathrm{Ca}^{2+}$ homeostasis of T-ALL cells and how PLC $\beta$ s are activated upon anti-CD3 stimulation of these cells. These heretofore unresolved fundamental issues are crucial for understanding the signalling pathways required for PLC activation and $\mathrm{Ca}^{2+}$ homeostasis in T-ALL cells.

Oxysterol-binding protein (OSBP)-related protein 4 (ORP4; also known as OSBP2) is present as three major variants, ORP4L, ORP4M and ORP4S ${ }^{17,18}$. ORP4 is expressed constitutively in brain, heart and testis, but is virtually absent from other human and mouse tissues ${ }^{17,19}$. ORP4 knockout mice exhibit teratozoospermia due to death of developing spermatozoa, indicating that ORP4 is essential for the survival of specific cell populations ${ }^{19}$. Early studies reported that ORP4L was detectable in leukocytes from patients with chronic myeloid leukemia but not healthy donors ${ }^{20,21}$. Recent reports have consistently indicated that ORP4L is involved in tumour cell proliferation and survival ${ }^{18}$ and a target of the natural antiproliferative steroidal saponin, OSW-1 (ref. 22), suggesting the involvement of ORP4L in control of oncogenic cell growth.

In the present study, we report the importance of elevated ORP4L expression in $G$ protein-coupled ligand-induced PLC activation in T-ALL cells and identify ORP4L as a major node in $\mathrm{Ca}^{2}+$ homeostasis, bioenergetics and survival of these cells.

\section{Results}

Elevated ORP4L expression is related to increased respiratory rate. In contrast to most cancer cells that rely on 'aerobic glycolysis' as the major source of ATP, leukocytes from patients with acute lymphocytic leukemia are characterized by high respiratory rates and low aerobic glycolysis ${ }^{23}$. To gain insights into the metabolic regulation of T-ALL cells, we first performed bioenergetics analyses in normal T-cells and primary T-ALL cells. We found significantly elevated cellular ATP levels (Fig. 1a) and increases of ATP in both the mitochondria and the cytosol (Supplementary
Fig. 1a,b) of primary T-ALL cells. This robust energy production is further underlined by the increased rate of basic oxygen consumption (OCR; Fig. 1b) accompanied by a significantly increased reactive oxygen species (ROS) production (Supplementary Fig. 1c). In most other types of cancer, aerobic glycolysis characterized by lactate production is hyperactive ${ }^{24}$. This does not appear to be the case in primary T-ALL cells (Fig. 1b). Oligomycin (Oli) and FCCP inhibit mitochondrial respiration and force cells to the glycolytic pathway to maintain energy supply; treatment with these agents is indicative of the reserve cellular glycolytic potential. Normal T-cells displayed a significant increase of the aerobic glycolysis under oligomycin and FCCP treatment (Fig. 1c). Whereas, primary T-ALL cells and T-ALL cell lines including Jurkat, Molt-4, CEM and MT-4 cells showed a decreased potential to upregulate the glycolytic machinery (Fig. 1c; Supplementary Fig. 1d). Furthermore, the glycolysis inhibitor 2-deoxy-dglucose (2-DG) slightly decreased ATP generation in normal T-cells (Fig. 1d). In contrast, primary T-ALL cells and T-ALL cell lines exhibited a significant decrease of ATP upon oligomycin treatment, but were resistant to a drop of cellular ATP induced by 2-DG (Fig. 1d; Supplementary Fig. 1e).

Because previous studies suggested expression of ORP4L in leukocytes from patients with chronic myeloid leukemia ${ }^{20,21}$, we compared ORP4L expression in normal T-cells and primary T-ALL cells. High levels of ORP4L mRNA and protein were detected in all 18 primary T-ALL specimens (Supplementary Table 1) but not in normal T-cells (Fig. 1e,f). All of the T-ALL cell lines used above also displayed high ORP4L expression (Fig. 1g). Next, we infected primary T-ALL cells and cell lines with lentivirus carrying a small hairpin RNA (shRNA) targeting ORP4L (shORP4L) or ORP4L cDNA, and confirmed the knockdown and overexpression of ORP4L in these cells (Supplementary Fig. 2a-d). Surprisingly, ORP4L depletion in primary T-ALL and cell lines resulted in a reduction of cellular OCR (Fig. 1h; Supplementary Fig. 2e) and ATP levels (Fig. 1i; Supplementary Fig. 2f), whereas ORP4L overexpression increased these parameters (Fig. 1j,k; Supplementary Fig. 2g,h). To exclude off-target effects of ORP4L shRNA, we also performed rescue experiments in ORP4L knockdown Jurkat T-cells, overexpression of ORP4L abolished the OCR and ATP decrease upon ORP4L knockdown (Supplementary Fig. 2i). These results indicated that ORP4L is required for the energy homeostasis of T-ALL cells.

Aberrant Notch-1 signalling has a major role in the pathogenesis of T-ALL, as more than $60 \%$ of T-ALL cases harbour activating mutations in the NOTCH-1 gene ${ }^{25}$. Most T-ALL cell lines harbouring activating mutations in $\mathrm{NOTCH}-1$ fail to respond to small-molecule $\gamma$-secretase inhibitors (GSIs) therapy, owing to mutational loss of the phosphatase and tensin homolog (PTEN) tumour suppressor ${ }^{26}$. We detected Notch-1 and PTEN status in all $18 \mathrm{~T}$-ALL primary samples. Among the 18 cases, 10 have activating mutations that involve the extracellular heterodimerization domain and/or the C-terminal PEST domain of NOTCH-1, and 7 of the 18 samples display PTEN loss (Supplementary Fig. 3a). However, the expression of ORP4L is independent of the Notch-1 and PTEN status. Recently, PTEN-null T-ALL cells were shown to display upregulated glycolysis ${ }^{27}$ as compared with PTEN-positive cells. Jurkat, CEM and Molt- 4 are PTEN-null cell lines, and MT- 4 cells are PTENpositive (Supplementary Fig. 3b). However, all of these cell lines were unable to resort to glycolysis in response to uncoupling of respiration (Fig. 1c,d; Supplementary Fig. 1d,e). These results support the notion that T-ALL cells may paradoxically depend more on mitochondrial oxidative phosphorylation than glycolysis to meet their energy demands. 


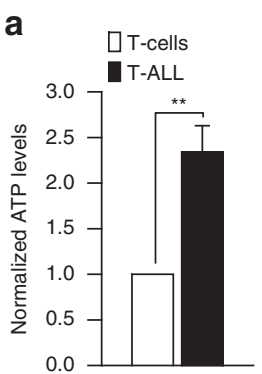

b

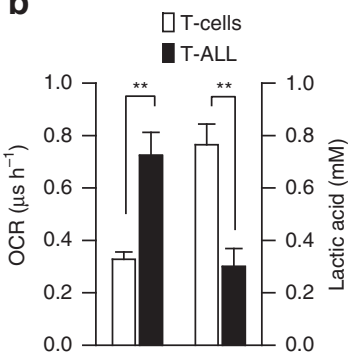

c

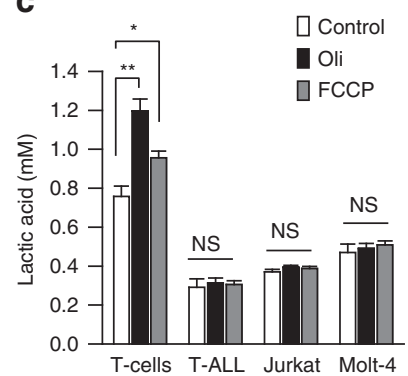

f e

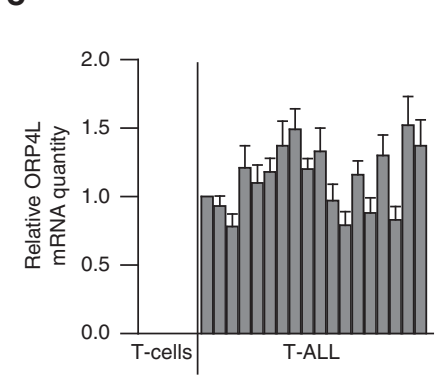

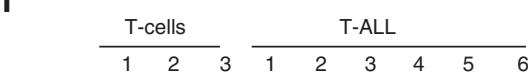

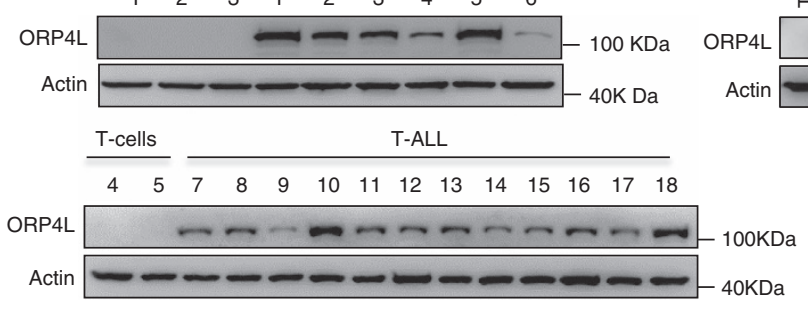

d

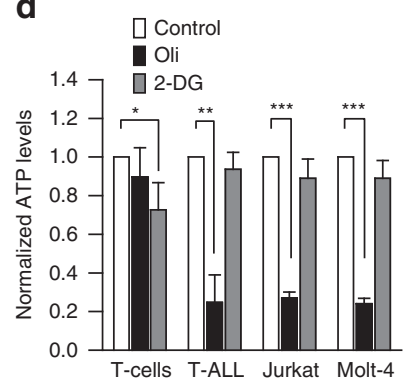

h

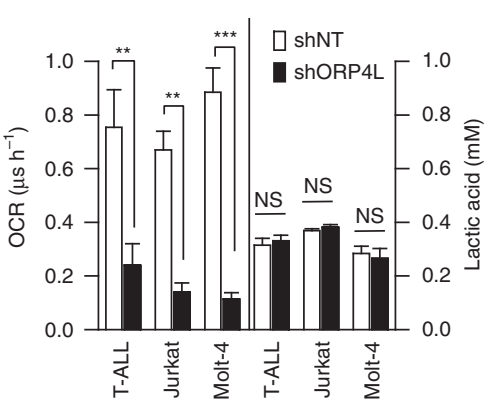

i

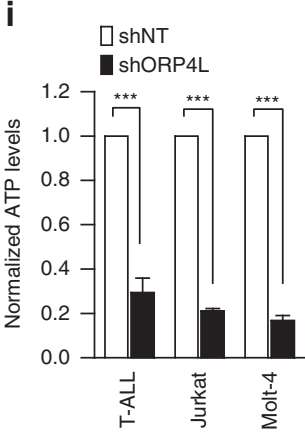

j

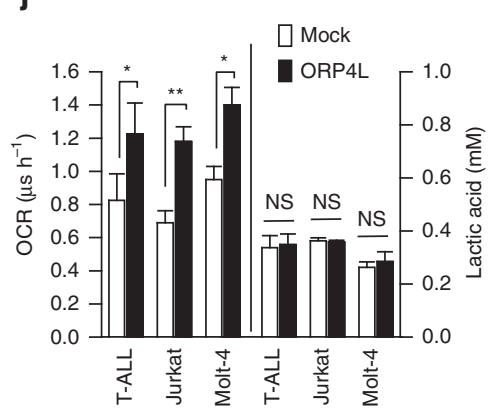

k

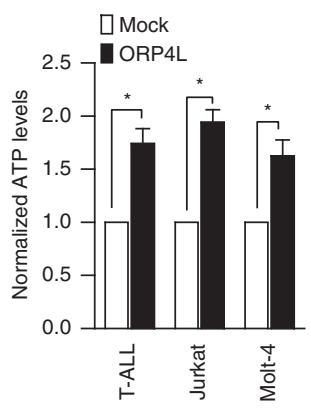

Figure 1 | Elevated ORP4L expression is concurrent with aberrant energy metabolism in T-ALL cells. (a) ATP levels were measured in normal T-cells $(n=5)$ and primary T-ALL cells $(n=8)$. (b) Baseline OCR and lactic acid levels in normal T-cells $(n=4)$ and primary T-ALL cells $(n=6)$. (c) Lactic acid levels in normal T-cells $(n=4)$, primary T-ALL cells $(n=6)$, Jurkat T-cells and Molt-4 cells after treatment of oligomycin $(\mathrm{Oli}, 5 \mu \mathrm{M})$ or FCCP $(5 \mu \mathrm{M})$ for $4 \mathrm{~h}$. (d) ATP levels were measured in normal T-cells $(n=4)$, primary T-ALL cells $(n=3)$, Jurkat T-cells and Molt-4 cells after treatment with oxidative phosphorylation inhibitor oligomycin (Oli, $5 \mu \mathrm{M}$ ) or glycolysis inhibitor (2-DG, $5 \mu \mathrm{M})$ for $6 \mathrm{~h}$. (e,f) ORP4L mRNA (e) and protein expression (f) in normal T-cells and primary T-ALL cells. (g) ORP4L expression in normal T-cells and T-ALL cell lines. (h) Baseline OCR and lactic acid levels in primary T-ALL cells $(n=3)$, Jurkat T-cells and Molt-4 cells with ORP4L knockdown. (i) ATP levels in primary T-ALL cells $(n=3)$, Jurkat T-cells and Molt-4 cells with ORP4L knockdown. (j) Baseline OCR and lactic acid levels in primary T-ALL cells $(n=3)$, Jurkat T-cells and Molt-4 cells with ORP4L overexpression. (k) ATP levels in primary T-ALL cells $(n=3)$, Jurkat T-cells and Molt-4 cells with ORP4L overexpression. The data represent mean \pm s.d. value from an experiment performed in triplicate. ${ }^{\star} P<0.05,{ }^{\star \star} P<0.01,{ }^{\star \star \star} P<0.001$, NS, not significant, Student's $t$ test.

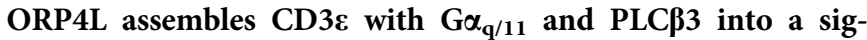
nalling complex. To address the mechanistic role of ORP4L in the energy homeostasis of T-ALL cells, we carried out a proteomic analysis of ORP4L-interacting components in Jurkat T-cells with an antibody specific for ORP4L. Anti-ORP4L and control IgG immunoprecipitates of cells stimulated with antiCD3 were separated on SDS-PAGE (Fig. 2a), and polypeptides specifically associated with ORP4L were identified by mass spectrometry. A total of 14 proteins were identified as potential ORP4L binding partners by subtracting proteins precipitated by control IgG from those identified in anti-ORP4L precipitated specimens (Supplementary Table 2). CD $3 \varepsilon, G \alpha_{q / 11}$ and PLC $\beta 3$ were among these candidates; the finding was confirmed by western blot analysis of the immunoprecipitates (Fig. 2a). Binding of $\mathrm{G} \alpha_{\mathrm{q} / \mathbf{1 1}}$ to $\mathrm{CD} 3 \varepsilon$ is activated upon anti-CD3 stimulation ${ }^{28}$, and these proteins can associate with PLC $\beta$ for signal transduction $^{29,30}$. Physical interactions between ORP4L and its binding partners were further investigated by co-immunoprecipitation. In the absence of anti-CD3 treatment, low levels of complexes of $\mathrm{CD} 3 \varepsilon$ and PLC $\beta 3$ were detected. On anti-CD3 stimulation, interaction of ORP4L with these two proteins increased in a timedependent manner, but no difference was observed in the association of ORP4L and $\mathrm{G} \alpha_{\mathrm{q} / 11}$ (Fig. 2b). The interactions between ORP4L, CD $3 \varepsilon, G \alpha_{\mathrm{q} / 11}$ and PLC $\beta 3$ raised the possibility that ORP4L could be required for the $\mathrm{CD} 3 \varepsilon-\mathrm{G} \alpha \mathrm{q}_{\mathrm{q} / 11}$ or $\mathrm{G} \alpha_{\mathrm{q} / 11}-\mathrm{PLC} \beta 3$ interactions. To test this hypothesis, we performed co-immunoprecipitation with anti-G $\alpha_{\mathrm{q} / 11}$ in Jurkat T-cells with ORP4L knockdown. G $\alpha_{\mathrm{q} / 11}$ was bound to CD3 $\varepsilon$ and PLC 33 upon anti-CD3 stimulation, but the binding was reduced in ORP4L knockdown cells (Fig. 2c). Moreover, immunodepletion/immunoprecipitation experiments revealed that ORP4L depletion markedly reduced the $\mathrm{CD} 3 \varepsilon-\mathrm{G} \alpha_{\mathrm{q} / 11}$ and $\mathrm{G} \alpha_{\mathrm{q} / 11}-\mathrm{PLC} \beta 3$ interactions (Fig. 2d). Normal T-cells exhibited no detectable ORP4L protein expression, and $\mathrm{G} \alpha_{\mathrm{q} / 11}$ failed to bind to $\mathrm{CD} 3 \varepsilon$ and PLC $\beta 3$ upon anti-CD3 stimulation of these cells (Fig. 2e). The above results strongly suggest that ORP4L acts 


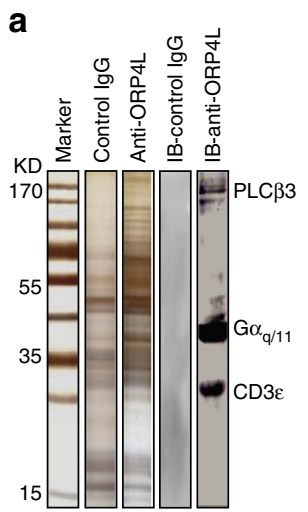

b

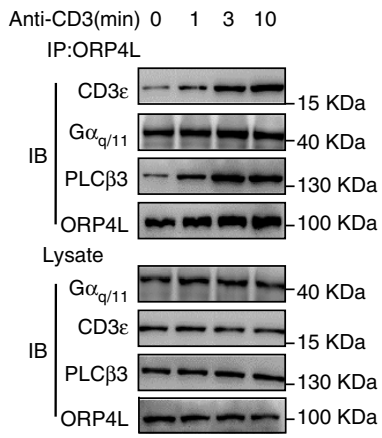

C

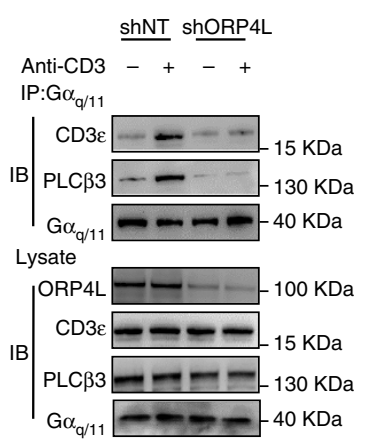

d

e $\mathbf{f}$

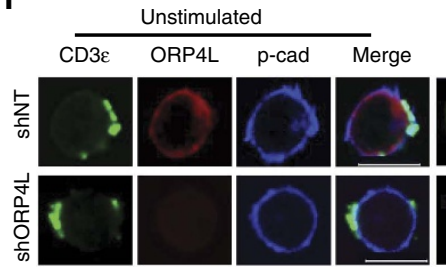

h

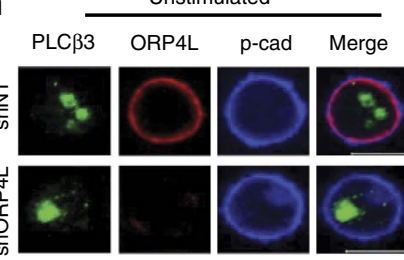

j

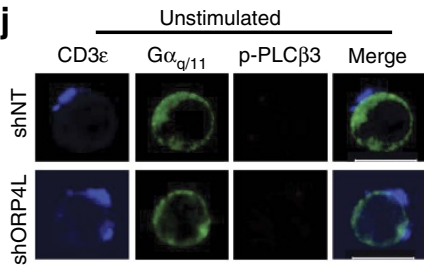

Anti-CD3 stimulation
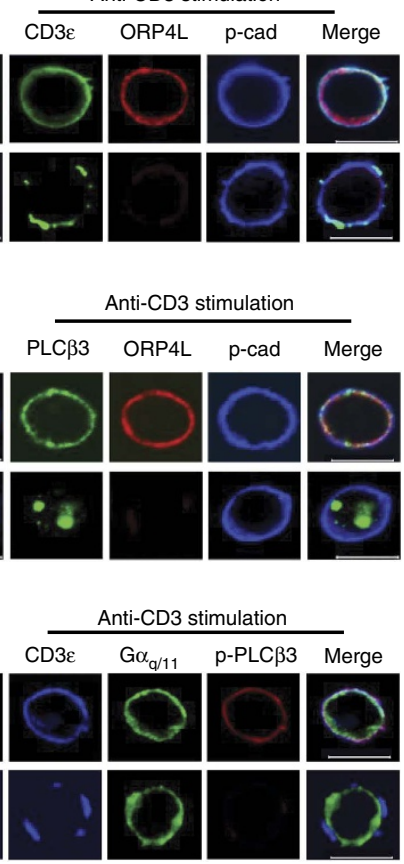

g

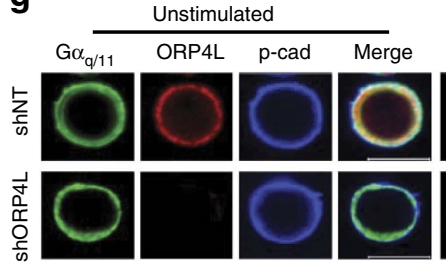

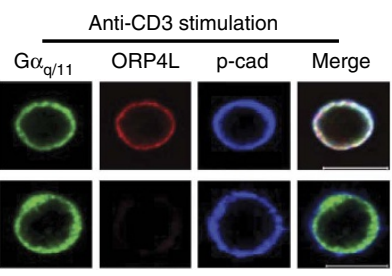

i

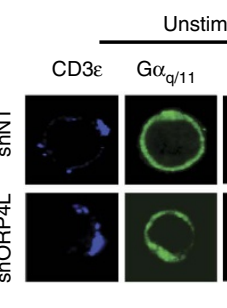

Depleted with

Anti-ORP4L

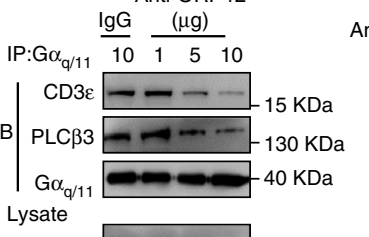

Anti-CD3(min) $0 \quad 10$

$\mathrm{IP}: G \alpha_{\alpha / 11}$

$\mathrm{IB} \mid \begin{gathered}\mathrm{CD} 3 \varepsilon \square- \\ \mathrm{PLC} 33 \\ \mathrm{G} \alpha_{\alpha / 11}\end{gathered}-15 \mathrm{KDa}$

Lysate

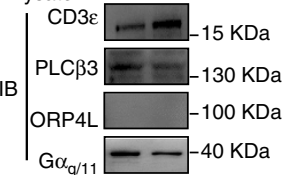

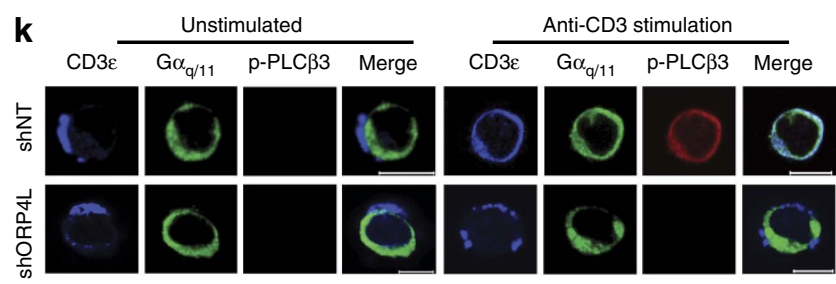

Figure 2 | ORP4L facilitates assembly of a signalling complex in T-ALL cells. (a) SDS-PAGE gel silver-stained for control lgG and anti-ORP4L immunoprecipitated proteins from Jurkat T-cells. The lane marked IB displays control IgG and anti-ORP4L immunoprecipitated proteins analyzed by western blot with anti-PLC $\beta 3, \mathrm{G} \alpha_{\mathrm{q} / 11}$ and CD3E antibodies simultaneously. (b) Co-immunoprecipitation analysis of ORP4L binding proteins in Jurkat T-cells. Cells were incubated with $10 \mu \mathrm{g} \mathrm{ml}^{-1}$ of anti-CD3 for the indicated times before lysates. (c) Co-immunoprecipitation analysis of $\mathrm{G} \alpha_{\mathrm{q} / 11}$ binding to CD3 $\varepsilon$ and PLC 33 in control and ORP4L knockdown cells. Cells were infected with shNT or shORP4L lentivirus for $72 \mathrm{~h}$, and then incubated with or without $10 \mu \mathrm{g} \mathrm{ml}^{-1}$ of anti-CD3 for 5 min before lysates. (d) Co-immunoprecipitation analysis of $\mathrm{G} \alpha_{\mathrm{q} / 11}$ binding to CD3E and PLC $\beta 3$ in Jurkat T-cell lysates before immunodepletion with ORP4L antibody. (e) Co-immunoprecipitation analysis $\mathrm{G} \alpha_{\mathrm{q} / 11}$ binding to CD3E and PLC $\beta 3$ in normal T-cells. Cells were incubated

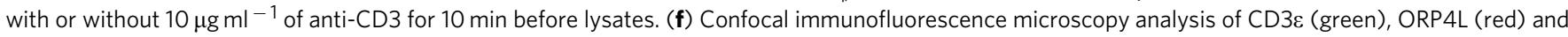
pan-Cadherin (blue) localization in shNT and shORP4L transduced Jurkat T-cells. Scale bars, $10 \mu \mathrm{m}$. (g) Confocal immunofluorescence microscopy analysis of $\mathrm{G} \alpha_{\mathrm{q} / 11}$ (green), ORP4L (red) and pan-Cadherin (blue) localization in shNT and shORP4L transduced Jurkat T-cells. Scale bars, $10 \mu \mathrm{m}$. (h) Confocal immunofluorescence microscopy analysis of PLCB3 (green), ORP4L (red) and pan-Cadherin (blue) localization in shNT and shORP4L transduced Jurkat T-cells. Scale bars, $10 \mu \mathrm{m}$. (i-k) Confocal microscopy analysis of CD3e (blue), G $\alpha_{q / 11}$ (green) and p-PLC $\beta 3$ (red) localization in shNT and shORP4L transduced Jurkat T-cells (i), Molt-4 cell (j) and primary T-ALL cells ( $\mathbf{k})$. Scale bars, $10 \mu \mathrm{m}$. For the confocal immunofluorescence above, cells were infected with shNT or shORP4L lentivirus for $72 \mathrm{~h}$ and then stimulated before staining for $5 \mathrm{~min}$ with or without $10 \mu \mathrm{g} \mathrm{ml}^{-1}$ anti-CD3.

as an adaptor that couples $\mathrm{CD} 3 \varepsilon, \mathrm{G} \alpha_{\mathrm{q} / 11}$ and PLC $\beta 3$ upon antiCD3 stimulation.

Confocal imaging analyses showed that $\mathrm{CD} 3 \varepsilon$ clustered in a non-uniform manner at the plasma membrane of unstimulated Jurkat T-cells. Anti-CD3 stimulation, however, induced a striking redistribution of $\mathrm{CD} 3 \varepsilon$ in the plasma membrane and increased its co-localization with ORP4L (Fig. 2f). In contrast, redistribution of CD3 $\varepsilon$ was not observed in ORP4L-depleted cells (Fig. 2f). G $\alpha_{q / 11}$ was distributed uniformly at the plasma membrane and co-localized with ORP4L; its location did not change upon antiCD3 stimulation or ORP4L depletion (Fig. 2g). PLC $\beta 3$ exhibited an intranuclear localization in unstimulated cells (Fig. 2h; Supplementary Fig. 4a). Anti-CD3 stimulation induced a partial but clear translocation of PLC $\beta 3$ to the plasma membrane where it co-localized with ORP4L (Fig. 2h). Cell fractionation followed by the western blot analysis provided further evidence for 
translocation of PLC 33 from the nucleus to the plasma membrane upon anti-CD3 stimulation (Supplementary Fig. 4b). Immunofluorescence experiments revealed localization of ORP4L at the plasma membrane, but most of this protein remained in the soluble cytosolic fraction after cell fractionation. To clarify the reason for this contradiction, we treated cells before lysis with membrane permeable cross-linking agent dithiobis-succinimidyl propionate (DSP). The intensity of the ORP4L band in plasma membrane fraction increased substantially after DSP treatment (Supplementary Fig. 4c), consistent with the view that ORP4L associates with plasma membrane via peripheral, weak or transient interactions and that the lysis procedure disrupts the association. Of note, ORP4L knockdown markedly inhibited the PLCB3 translocation upon anti-CD3 stimulation (Fig. 2h). The responding cell number and the quantity of translocated PLC $\beta 3$ protein were reduced in ORP4L knockdown cells (Supplementary Fig. 4d), which could be rescued by ORP4L overexpression (Supplementary Fig. 4e). Confocal imaging showed that the active phosphorylated form of PLC $\beta 3$ (p-PLC $\beta 3)^{31,32}$ was present only in the plasma membrane but not in the nucleus of anti-CD3 stimulated cells (Supplementary Fig. 4f), indicating that intranuclear PLC $\beta 3$ was inactive. Triple staining for CD $3 \varepsilon, G \alpha_{\mathrm{q} / 11}$ and p-PLC $\beta 3$ displayed a high degree of co-localization, consistent with the notion that these proteins are assembled into complexes upon anti-CD3 stimulation in Jurkat (Fig. 2i), Molt-4 (Fig. 2j) and primary T-ALL cells (Fig. 2k). Whereas, the co-localization was inhibited in cells subjected to ORP4L knockdown. To conclude, the present results thus suggest that ORP4L functions as an adaptor/scaffold for the assembly of CD3e, $G \alpha_{\mathrm{q} / 11}$ and PLC $\beta 3$ into a signalling complex.

ORP4L mediates $\mathrm{PLC} \beta 3$ activation and $\mathrm{IP}_{3}$ production. Functional relationships among the signalling complex components scaffolded by ORP4L were further interrogated. In Jurkat T-cells, anti-CD3 stimulation resulted in GTP exchange within $\mathrm{G} \alpha_{q / 11}$ (Fig. 3a), indicating the activation of this protein. ORP4L depletion inhibited the $\mathrm{G} \alpha_{\mathrm{q} / 11}$ activation, while its overexpression facilitated this activation (Fig. 3a). Moreover, phosphorylation of PLC $\beta 3$ and PLC activity upon anti-CD3 stimulation were abolished by $\mathrm{G} \alpha_{\mathrm{q} / 11}$ knockdown (Fig. 3b), indicating that PLC $\beta 3$ is under these conditions activated by $\mathrm{G} \alpha_{\mathrm{q} / 11}$. ORP4L knockdown decreased, whereas ORP4L overexpression increased p-PLC $\beta 3$ protein levels and PLC activity in Jurkat T-cells (Fig. 3c) and Molt-4 cells (Fig. 3d). These results demonstrate that PLC $\beta 3$ is activated in T-ALL cells by $G \alpha_{\mathrm{q} / 11}$, which requires the presence of ORP4L.

The prominent role of PLC $\beta 3$ in T-ALL cells was further clarified. PLC $\gamma 1$ knockdown decreased $\mathrm{IP}_{3}$ production and intracellular $\mathrm{Ca}^{2+}\left[\mathrm{Ca}^{2+}\right]_{\mathrm{i}}$ peak amplitude in normal T-cells upon anti-CD3 stimulation (Supplementary Fig. 5a), but no significant change was observed in primary T-ALL cells (Supplementary Fig. 5b) or Jurkat T-cells (Supplementary Fig. 5c). By contrast, PLC $\beta 3$ knockdown resulted in a significant reduction of $\mathrm{IP}_{3}$ production and $\left[\mathrm{Ca}^{2+}\right]_{i}$ peak amplitude in primary T-ALL (Supplementary Fig. 5b) and Jurkat T-cells (Supplementary Fig. 5c), while no such effect was observed in normal T-cells (Supplementary Fig. 5a). Overexpression of PLC 33 , but not PLC $\gamma 1$, increased IP 3 production and amplified $\left[\mathrm{Ca}^{2+}\right]_{i}$ peak amplitude in Jurkat T-cells (Supplementary Fig. 5d). These findings suggest that PLC $\gamma 1$ is essential for $\mathrm{IP}_{3}$ production and $\mathrm{Ca}^{2+}$ release in normal T-cells, whereas PLC $\beta 3$ is a major regulator of these responses in T-ALL cells.

ORP4L knockdown significantly reduced $\mathrm{IP}_{3}$ production in Jurkat T-cells, Molt-4 cells and primary T-ALL cells (Fig. 3e, left), while its overexpression significantly increased $\mathrm{IP}_{3}$ production
(Fig. 3e, right). Furthermore, overexpression of ORP4L rescued the $\mathrm{IP}_{3}$ level in ORP4L knockdown cells (Supplementary Fig. 6a), and the increased $\mathrm{IP}_{3}$ production upon overexpression of ORP4L was abrogated upon PLC $\beta 3$ silencing (Supplementary Fig. 6b). Also overexpression of PLC $\beta 3$ increased the $\mathrm{IP}_{3}$ production, an effect that was abolished upon ORP4L knockdown (Supplementary Fig. 6c). Exogenous $\mathrm{PIP}_{2}$ can increase $\mathrm{IP}_{3}$ production in a dose-dependent manner (Supplementary Fig. 6d, left panel). ORP4L depletion attenuated, while ORP4L overexpression increased the $\mathrm{PIP}_{2}$-induced $\mathrm{IP}_{3}$ production (Supplementary Fig. 6d, middle and right panels). Altogether, these findings strongly suggest that $\mathrm{ORP} 4 \mathrm{~L}$ regulates cellular $\mathrm{IP}_{3}$ production.

ORP4L modulates $\mathrm{Ca}^{2+}$ signalling in T-ALL cells. The function of ORP4L was further explored by assaying $\mathrm{Ca}^{2+}$ release in the cytosol. In agreement with the observed in $\mathrm{IP}_{3}$ production, ORP4L knockdown markedly reduced the $\left[\mathrm{Ca}^{2+}\right]_{\mathrm{i}}$ peak amplitude (Fig. 4a), whereas ORP4L overexpression enhanced the amplitude in anti-CD3 stimulated Jurkat T-cells (Fig. 4b). The similar results were observed in a $\mathrm{Ca}^{2+}$-free medium (Supplementary Fig. 7a,b). ORP4L manipulations had no effect on $\mathrm{Ca}^{2+}$ influx (Supplementary Fig. 7a,b), supporting the view that $\mathrm{Ca}^{2}+$ released upon ORP4L manipulation originates from the ER. Consistently, direct measurement of the ER $\mathrm{Ca}^{2+}$ revealed that in ORP4L knockdown cells the amplitude of ER $\mathrm{Ca}^{2+}$ depletion upon anti-CD3 stimulation was smaller than in controls, whereas ORP4L overexpression increased the depletion amplitude (Supplementary Fig. 7c,d). Thapsigargin (TG) -induced $\mathrm{Ca}^{2+}$ elevation is an indirect measure of ER $\mathrm{Ca}^{2+}$ content ${ }^{33}$. We found no difference in the magnitude of the TG releasable $\mathrm{Ca}^{2+}$ pool in control and ORP4L knockdown or overexpressing cells (Supplementary Fig. 7e,f). Moreover, the ORP4L manipulations did not affect the total amount of intracellular $\mathrm{Ca}^{2+}$ (Supplementary Fig. 7g). These results further support the conclusion that ORP4L regulates $\mathrm{Ca}^{2+}$ release from the ER.

Single cell confocal imaging of spontaneous $\left[\mathrm{Ca}^{2+}\right]_{\mathrm{i}}$ oscillations revealed transient $\left[\mathrm{Ca}^{2+}\right]_{i}$ spikes in $43 \%$ of control Jurkat T-cells. In contrast, spontaneous $\left[\mathrm{Ca}^{2+}\right]_{\mathrm{i}}$ spikes were observed in only $6 \%$ of ORP4L knockdown cells and at a lower frequency than in controls (0.08 versus 0.12 oscillations $\left.\mathrm{min}^{-1}\right)$ (Fig. 4c). Similar results were consistently obtained in Molt- 4 cells (Fig. 4d) and primary T-ALL cells (Fig. 4e). The pulsatile release of $\mathrm{Ca}^{2+}$ underlying $\left[\mathrm{Ca}^{2+}\right]_{i}$ oscillations is transmitted efficiently into the mitochondrial matrix, giving rise to associated oscillations of $\left[\mathrm{Ca}^{2+}\right]_{\mathrm{m}}$. ORP4L knockdown also reduced oscillations of $\left[\mathrm{Ca}^{2+}\right]$ $\mathrm{m}$ in Jurkat T-cells (Fig. 4f).

ER-mitochondrial contact sites are known to mediate $\mathrm{Ca}^{2+}$ transfer from ER to mitochondria ${ }^{34,35}$. We employed transmission electron microscopy and confocal microscopy to investigate the possibility that ORP4L could modify the ER-mitochondrial contact sites. The results failed to reveal a change in the quantity of ER-mitochondrial contacts in ORP4L knockdown cells (Supplementary Fig. 8a,b). Cholesterol is a critical component of biological membranes and has an essential role in mitochondrial fuctions ${ }^{36}$. Considering that ORP4L is a sterol-binding protein, we analyzed the effect of ORP4L silencing on cholesterol transport from the plasma membrane to ER and mitochondria using fluorescent BODIPY-cholesterol. After 1-h chase of the BODIPY-cholesterol label inserted in plasma membranes, no difference was observed between control and ORP4L knockdown cells in the transport of the tracer to either target organelle (Supplementary Fig. 9a,b). The present results thus suggest that ORP4L increases the release of $\mathrm{Ca}^{2+}$ from the 
a

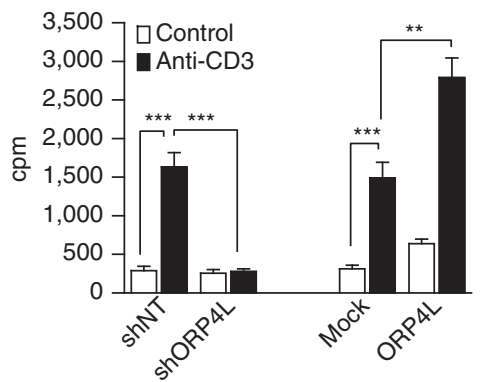

b

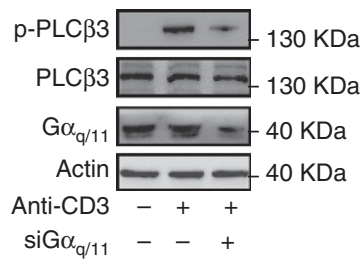

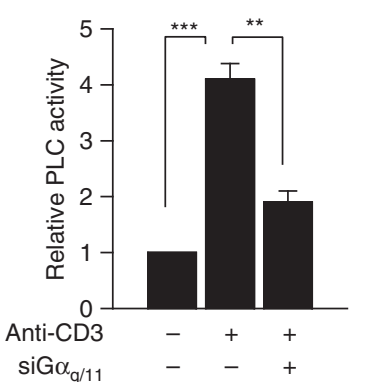

C

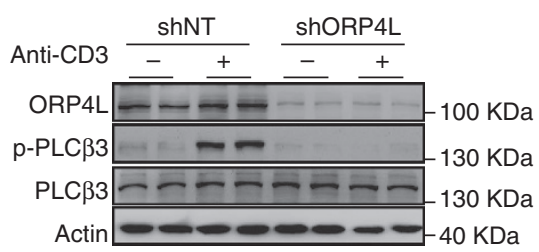
$40 \mathrm{KDa}$

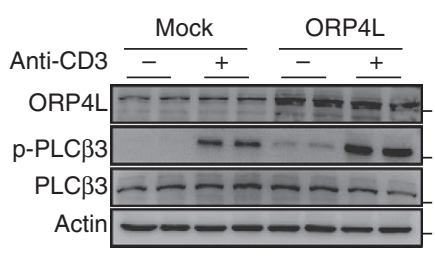

$-100 \mathrm{KDa}$

$130 \mathrm{KDa}$

$130 \mathrm{KDa}$ $40 \mathrm{KDa}$

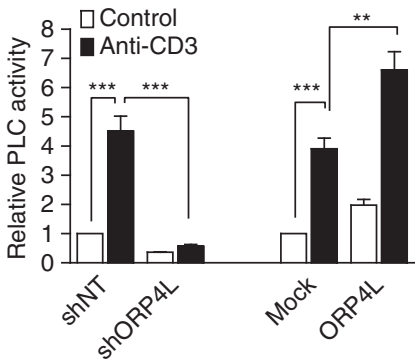

d

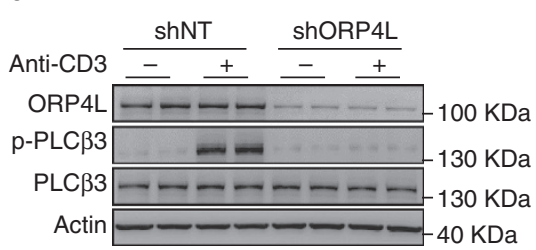

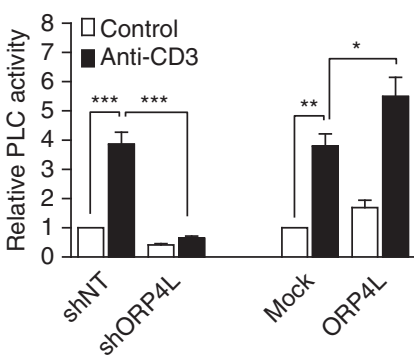

e
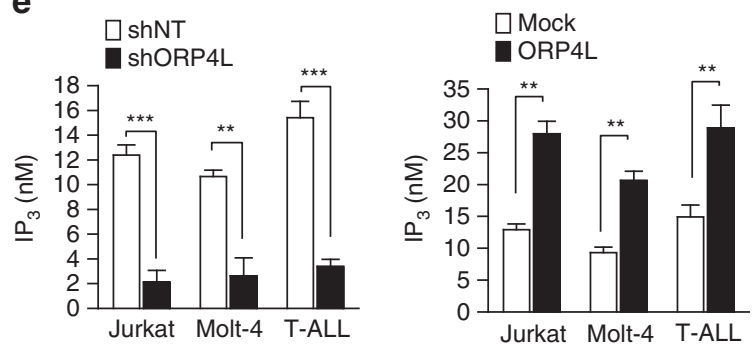

Figure 3 | ORP4L is required for PLC $\beta 3$ activation. (a) Specific $\left[{ }^{35} \mathrm{~S}\right] \mathrm{GTP} \gamma \mathrm{S}$ exchange in $\mathrm{G} \alpha_{\mathrm{q} / 11}$ in Jurkat T-cells with ORP4L knockdown or overexpression. Cells were stimulated with or without $10 \mu \mathrm{g} \mathrm{ml} \mathrm{m}^{-1}$ anti-CD3 for $5 \mathrm{~min}$ before analysis. (b) PLC $\beta 3$ phosphorylation and PLC activity in Jurkat T-cells with $\mathrm{G} \alpha_{\mathrm{q} / 11}$ knockdown induced with or without $10 \mu \mathrm{g} \mathrm{ml} \mathrm{I}^{-1}$ anti-CD3 for $5 \mathrm{~min}$. (c,d) PLC $\beta 3$ phosphorylation and PLC activity in Jurkat T-cells (c) and Molt-4 cells (d) with ORP4L knockdown or overexpression. Cells were stimulated with $10 \mu \mathrm{g} \mathrm{ml} \mathrm{m}^{-1}$ anti-CD3 for 5 min. (e) IP 3 production in Jurkat T-cells, Molt-4 cells and primary T-ALL cells $(n=3)$ with ORP4L knockdown (left) or overexpression (right). Cells were stimulated with $10 \mu \mathrm{g} \mathrm{ml}{ }^{-1}$ anti-CD3 for 5 min. The data represent mean \pm s.d. value from an experiment performed in triplicate, ${ }^{\star \star} P<0.01,{ }^{\star \star \star} P<0.001$, Student's $t$ test.

ER but most likely does not control ER-mitochondrial contacts or cholesterol transport to these compartments.

The OSBP2 gene encodes ORP4L as well as two truncated variants ORP4M and ORP4S ${ }^{18}$. Similar to ORP4L, ORP4M and ORP4S were detected in primary T-ALL specimens and T-ALL cell lines but not in normal T-cells as analyzed by reverse transcription-PCR (RT-PCR) (Supplementary Fig. 10a). To determine the role of ORP4M, ORP4S, the PH domain and the FFAT motif of ORP4 in the proposed pathway, we overexpressed a series of constructs in Jurkat T-cells (Supplementary Fig. 10b), followed by analysis of $\mathrm{IP}_{3}$ production and amplitude of $\mathrm{Ca}^{2+}$ release upon anti-CD3 stimulation. The results showed that ORP4M, ORP4S, the truncated fragment lacking the PH domain and the $\mathrm{PH}$ domain alone were unable to increase the $\mathrm{IP}_{3}$ production (Supplementary Fig. 10c) and the $\mathrm{Ca}^{2}+$ release (Supplementary Fig. 10d). However, the mutant with the FFAT motif inactivated retained the activities of ORP4L. These results indicated that the ORP4L PH domain is essential for the proposed pathway, while FFAT motif is not absolutely required.

ORP4L sustains $\mathrm{Ca}^{2+}$-based bioenergetics in T-ALL cells. $\mathrm{Ca}^{2+}$ oscillations released periodically from the ER are taken up by mitochondria via the $\mathrm{MCU}^{8}$, which stimulates mitochondrial dehydrogenases required for the maintenance of cell bioenergetics $^{9,10}$. Dephosphorylation of mitochondrial pyruvate dehydrogenase $(\mathrm{PDH})$ by a $\mathrm{Ca}^{2}{ }^{+}$-dependent phosphatase enhances its activity ${ }^{9}$. PDH was hyperphosphorylated in Jurkat, 
a

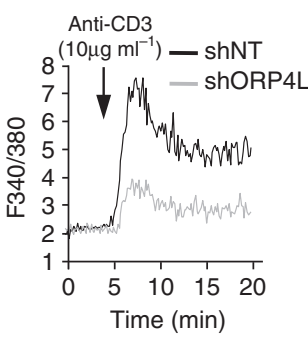

C

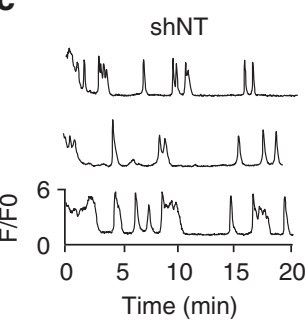

d

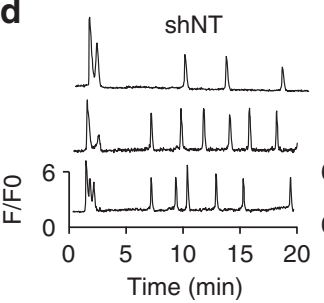

e

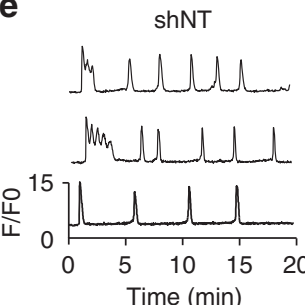

$\mathbf{f}$
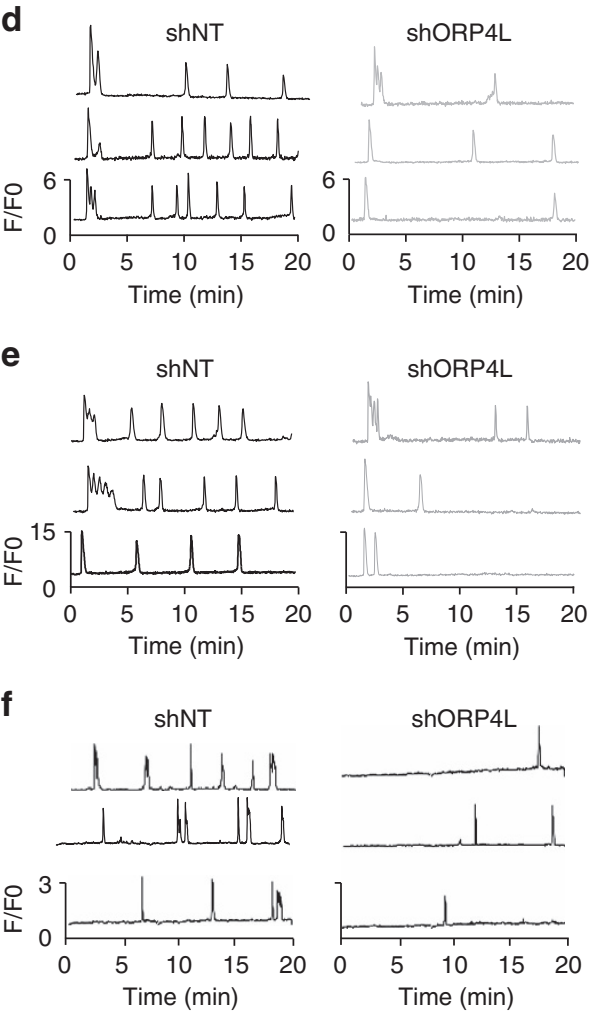

b
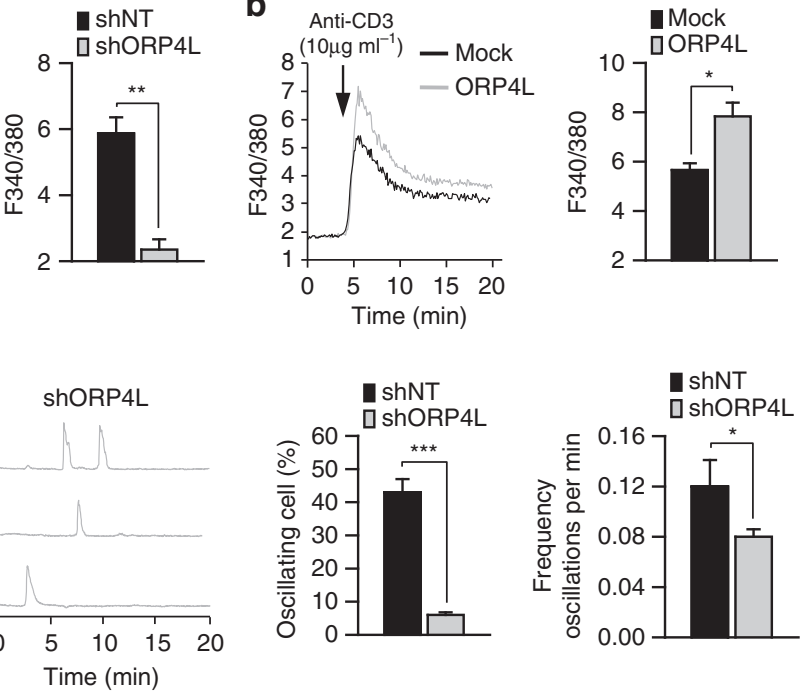
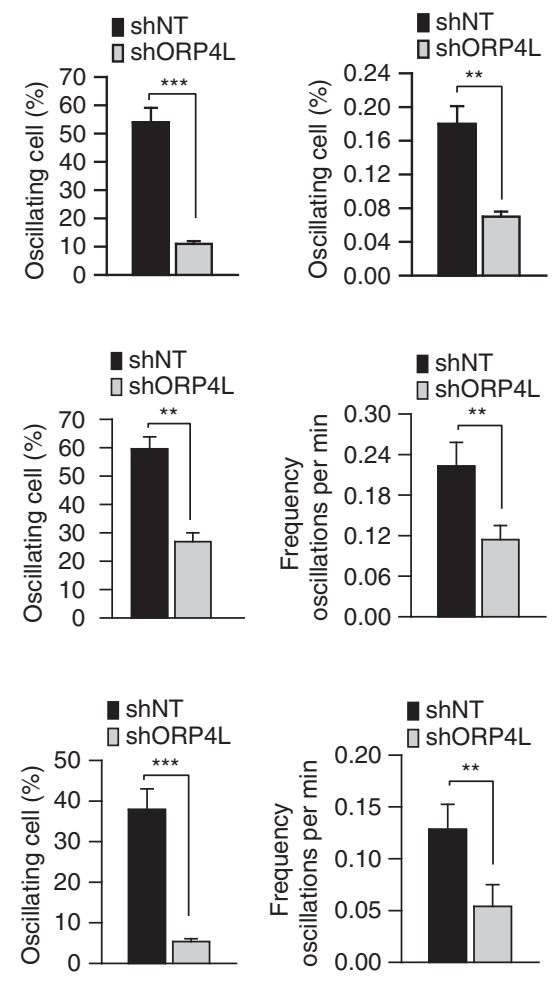

Figure 4 | ORP4L modulates $\mathbf{C a}^{2}+$ signalling in T-ALL cells. (a,b) Jurkat T-cells subjected to ORP4L knockdown (a) or overexpression (b) were stimulated with $10 \mu \mathrm{g} \mathrm{ml}^{-1}$ anti-CD3. Changes in $\left[\mathrm{Ca}^{2+}\right]_{i}$ were recorded as the F340/380 ratio using Fura-2 AM. Average $\left[\mathrm{Ca}{ }^{2+}\right]_{i}$ responses and quantification of $\left[\mathrm{Ca}^{2+}\right]_{i}$ peak amplitudes are shown. (c-e) Spontaneous $\left[\mathrm{Ca}^{2+}\right]_{i}$ oscillations in Jurkat T-cells (c), Molt-4 cells (d) and primary T-ALL cells (e) with ORP4L knockdown. Changes in $\left[\mathrm{Ca}^{2+}\right]_{i}$ were recorded as $\mathrm{F} / \mathrm{F}_{\mathrm{O}}$ ratio using Fluo-4-AM in confocal $\mathrm{Ca}^{2+}$ imaging. Spontaneous $\left[\mathrm{Ca}{ }^{2+}\right]_{i}$ oscillations in three representative cells (left) were measured, and the difference in frequency and number of oscillating cells is shown (right).

(f) Spontaneous $\left[\mathrm{Ca}^{2+}\right]_{\mathrm{m}}$ oscillations in Jurkat T-cells with ORP4L knockdown. Changes in $\left[\mathrm{Ca}^{2+}\right]_{\mathrm{m}}$ were recorded as $F / F_{0}$ ratio using Rhod-2-AM in confocal $\mathrm{Ca}^{2+}$ imaging. For the Jurkat T-cells the data represent mean \pm s.d. value from an experiment performed in triplicate, and for primary T-ALL cells the mean \pm s.d. value of $n=3$ primary T-ALL specimens. ${ }^{\star} P<0.05$, ${ }^{\star \star} P<0.01,{ }^{\star \star \star} P<0.001$, Student's $t$ test.

Molt-4 and primary T-ALL cells with ORP4L knockdown (Fig. 5a), whereas ORP4L overexpression reduced $\mathrm{PDH}$ phosphorylation (Fig. 5b). To strengthen the link between ORP4L, $\mathrm{Ca}^{2+}$ signalling and mitochondrial metabolism, we analyzed $\mathrm{PDH}$ phosphorylation, OCR and ATP levels in ORP4L manipulated Jurkat T-cells subjected to PLCß3 knockdown or a series of inhibitor/agonist treatments. $\mathrm{PDH}$ dephosphorylation, OCR and ATP production increase induced by ORP4L overexpression were abolished by PLC $\beta 3$ knockdown (Fig. 5c), by the PLC inhibitor U73122 and the $\operatorname{InsP}_{3} \mathrm{R}$ inhibitor xestospongin $\mathrm{C}$ (XeC) (Fig. 5d). The effects of ORP4L knockdown on increased PDH phosphorylation, reduced OCR and ATP levels were rescued by the $\mathrm{Ca}^{2}+$ transporter ionomycin (Fig. 5e) and the MCU agonist kaempferol ${ }^{37}$ (Fig. 5g). By 
a

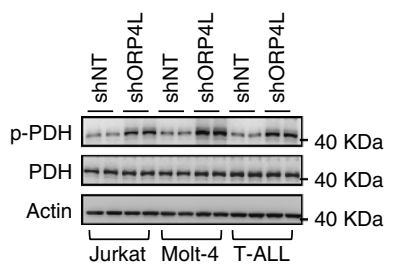

b

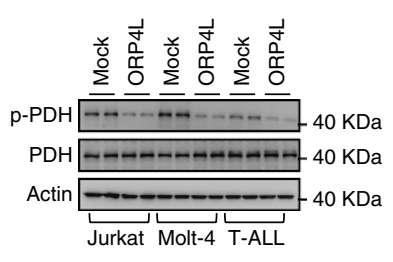

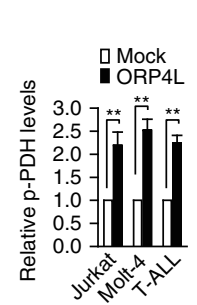

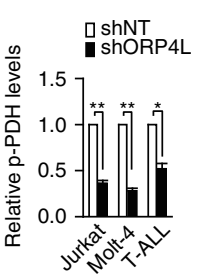

c

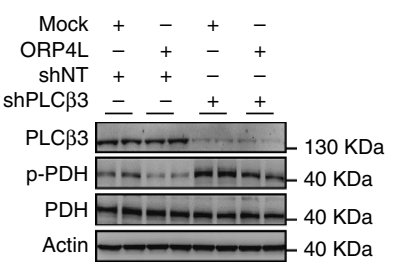

d

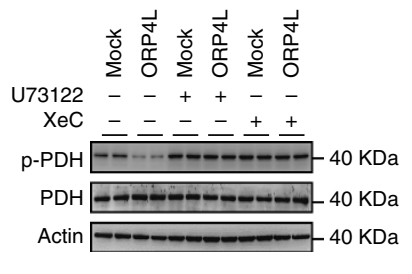

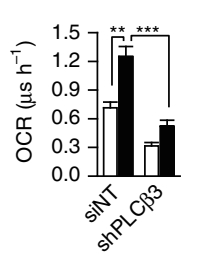

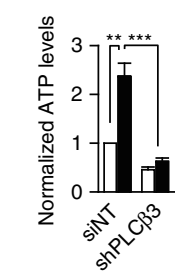

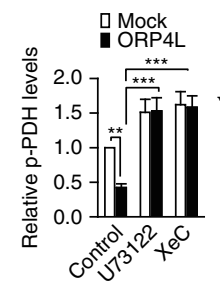

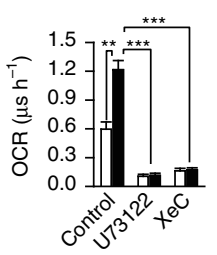

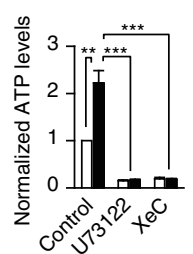
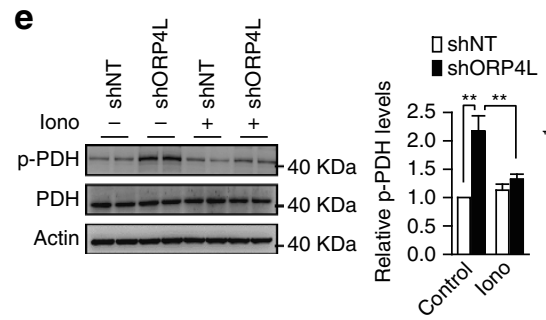

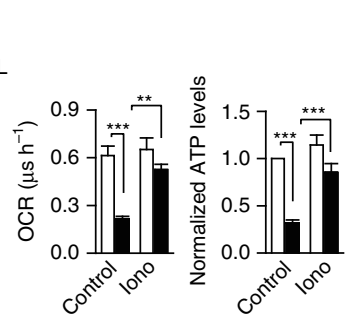

f

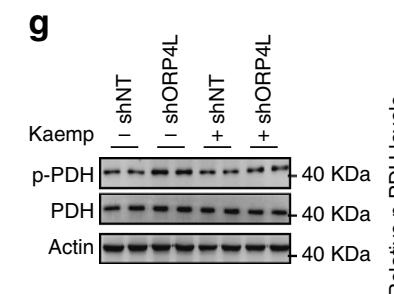

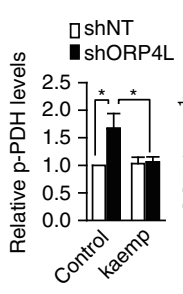

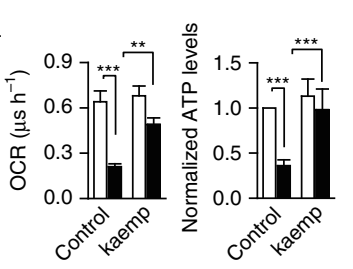

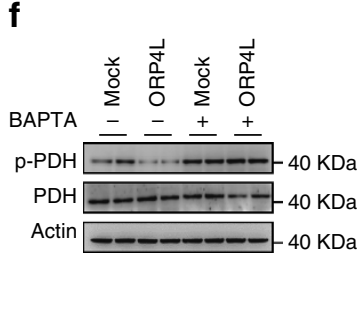
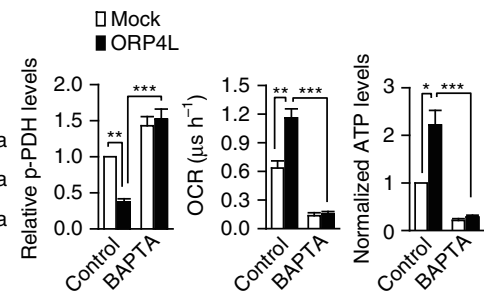

h

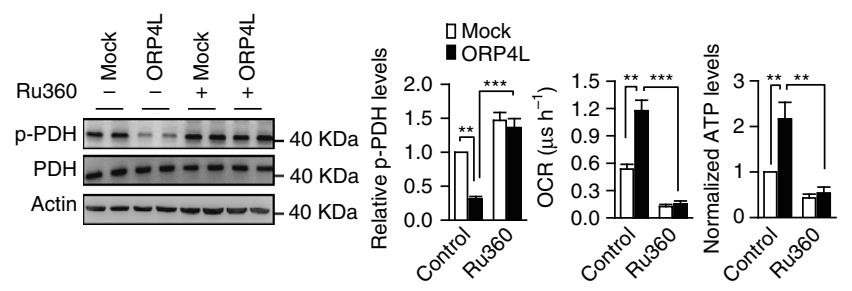

i

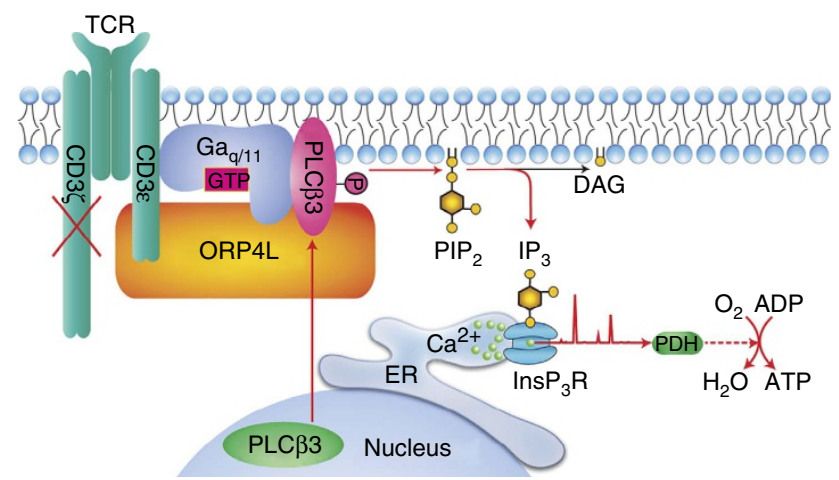

Figure 5 | ORP4L sustains $\mathbf{C a}^{2}{ }^{+}$-dependent bioenergetics in T-ALL cells. (a,b) Western blot analysis of PDH activation in Jurkat, Molt-4 and primary T-ALL cells with ORP4L knockdown (a) and overexpression (b). p-PDH/PDH expressed as fold change over control. (c) PDH activation (left), OCR (middle) and ATP levels (right) in Jurkat T-cells with ORP4L knockdown alone or in combination with shPLC 33 . (d) PDH activation (left), OCR (middle) and ATP levels (right) in control or ORP4L overexpressing Jurkat T-cells treated with or without U73122 ( $5 \mu \mathrm{M}$ for $1 \mathrm{~h})$ or XeC ( $2 \mu \mathrm{M}$ for $1 \mathrm{~h})$. (e) PDH activation (left), OCR (middle) and ATP levels (right) in control or ORP4L knockdown Jurkat T-cells treated with or without ionomycin ( $\left.2 \mathrm{mg} \mathrm{I}^{-1} \mathrm{for} 1 \mathrm{~h}\right)$. (f) PDH activation (left), OCR (middle) and ATP levels (right) in control or ORP4L overexpressing Jurkat T-cells treated with or without BAPTA-AM (50 $\mu$ M for $1 \mathrm{~h}$ ). (g) PDH activation (left), OCR (middle) and ATP levels (right) in control or ORP4L knockdown Jurkat T-cells treated with or without MCU agonist, kaempferol ( $2 \mu \mathrm{M}, 30 \mathrm{~min})$. (h) PDH activation (left), OCR (middle) and ATP levels (right) in control or ORP4L overexpressing Jurkat T-cells treated with or without MCU inhibitor, RU360 ( $5 \mu \mathrm{M}, 30 \mathrm{~min})$. The data represent mean \pm s.d. value from an experiment performed in triplicate. ${ }^{\star} P<0.05$, ${ }^{\star \star} P<0.01$,

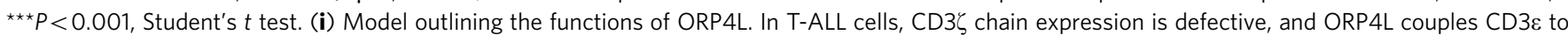
$\mathrm{PLC} \beta 3 / \mathrm{G} \alpha_{\mathrm{q} / 11}$ to control the relocation and activation of $\mathrm{PLC} \beta 3$, which leads to increased $\mathrm{IP}_{3}$ generation and $\mathrm{Ca}^{2}+$ release from ER required for sustaining of cell bioenergetics. 
contrast, PDH dephosphorylation and increased OCR and ATP levels upon ORP4L overexpression could be abolished by the $\mathrm{Ca}^{2+}$ chelating agent BAPTA (Fig. 5f) and the MCU inhibitor RU360 (Fig. 5h). Energy produced during mitochondrial respiration is maintained as a high membrane potential ${ }^{38}$, which is mediated through a $\mathrm{Ca}^{2+}$-dependent mechanism ${ }^{39}$. ORP4L knockdown significantly reduced the mitochondrial membrane potential and $\mathrm{NAD}(\mathrm{P}) \mathrm{H}$ autofluorescence (Supplementary Fig. 11a,b). These findings suggest that ORP4L facilitates via stimulation of $\mathrm{IP}_{3}$ production and $\mathrm{ER} \mathrm{Ca}^{2}+$ release the delivery of $\mathrm{Ca}^{2+}$ to mitochondria and thereby regulates the phosphorylation of $\mathrm{PDH}$ to maintain mitochondrial bioenergetics (Fig. 5i).

It was obviously of interest to study whether forced expression of ORP4L in normal T-cells would be sufficient to divert their energy metabolism toward robust oxidative phosphorylation. After transfecting ORP4L into normal T-cells (Supplementary Fig. 12a), we analyzed $\mathrm{IP}_{3}$ production, OCR and ATP production, but found no significant difference between control and ORP4L overexpressing cells (Supplementary Fig. 12b). These findings suggest that, although ORP4L is necessary for the reprogramming of T-ALL cell bioenergetics, it is alone not sufficient to induce the process when overexpressed acutely.

ORP4L is essential for T-ALL cell survival in vitro and in vivo. In studies assessing the overall role of ORP4L in T-ALL cells, we found that ORP4L expression was positively correlated with Jurkat T-cell proliferation (Fig. 6a). ORP4L knockdown strongly accelerated Jurkat T-cells (Fig. 6b) and primary T-ALL cells death (Fig. 6c). A xenograft model was established in NOD/SCID mice to determine the contribution of ORP4L to T-ALL cell survival in vivo. Mice were injected with primary T-ALL cells infected with either shORP4L- or control shNTlentivirus. At 2 weeks post-injection engraftment had occurred in eight of nine mice injected with shNT cells but only in three of nine of mice receiving shORP4L cells (Fig. 6d, left panel). Moreover, the percentage of engrafted cells was markedly lower in mice injected with shORP4L cells (Fig. 6d, right panel and Fig. 6e).

Defective $\mathrm{Ca}^{2+}$ transfer from the ER to the mitochondria results in activation of the cellular energy sensor AMP kinase (AMPK), which induces autophagy ${ }^{9}$. To understand the pathway of cell death upon ORP4L knockdown, we analyzed the phosphorylation/activation of AMPK, and found that phosphoAMPK (p-AMPK) significantly increased upon ORP4L knockdown (Fig. 6f). Also, elevated autophagy upon ORP4L knockdown was detected by measurements of the autophagy marker LC3 II as well as increased LC3 puncta observed by immunofluorescence microscopy (Fig. 6f). Enhanced AMPK activity can in certain cases induce autophagy by inhibition of $\mathrm{mTOR}^{40}$. Nevertheless, mTOR phosphorylation at Ser2448 was similar in control and ORP4L knockdown cells (Fig. 6f), indicating that AMPK activation, but not inhibition of mTOR, is required for enhanced autophagy induced in the absence of ORP4L.

Autophagy can either suppress or support the growth of cancer cells depending on the cellular context ${ }^{2}$. Autophagy in the ORP4L knockdown cells was inhibited by the AMPK inhibitor compound C (Fig. 6g), indicating that AMPK is upstream of the autophagy induction in ORP4L knockdown cells. The death of these cells was markedly reduced by the inhibitor of autophagy, 3-MA (Fig. 6h). Consistent with the results in Jurkat T-cells, ORP4L knockdown activated PDH and AMPK, and enhanced autophagy also in primary T-ALL cells (Fig. 6i).

\section{Discussion}

We confirmed herein that, in contrast to normal T-cells, T-ALL cells preferentially utilize robust oxidative phosphorylation as a source of ATP, similar to a recent observation in chronic lymphocytic leukemia cells $s^{38}$ and leukemia stem cells $^{41}$. Our novel finding is that PLC $\beta 3$, activated through G proteindependent signal transduction, serves as a major enzyme for $\mathrm{IP}_{3}$ generation and intracellular $\mathrm{Ca}^{2+}$ and energy homeostasis in T-ALL cells, due to a selective up-regulation of ORP4L in malignant transformed T-cells.

Upon analysis of the underlying molecular mechanisms, we found that ORP4L specifically interacts with $C D 3 \varepsilon, G \alpha_{q / 11}$ and PLCB3. Anti-CD3 stimulation enhanced these interactions, suggesting assembly of a signalling complex upon anti-CD3 stimulation. Immunodepletion/co-immunoprecipitation assays showed that the binding of $C D 3 \varepsilon$ to $G \alpha_{q / 11}$, crucial for PLC $\beta 3$ activation, depends on ORP4L. In addition, confocal imaging showed CD3E and PLC $\beta 3$ redistribution and co-localization with $\mathrm{G \alpha}_{\mathrm{q} / 11}$ only in the presence of ORP4L. Taken together, these findings suggest that ORP4L acts as an adaptor/scaffold to recruit CD3 $\varepsilon, G \alpha_{q / 11}$ and PLC $\beta 3$ for the formation of a G proteindependent signalling complex in T-ALL cells.

PLCs perform a catalytic function at the plasma membrane where their substrate, $\mathrm{PIP}_{2}$, is localized. However, PLCs also exist at other subcellular locations such as the cytoplasm and the nucleus ${ }^{42,43}$. This separation of an enzyme from its substrates represents an important regulatory mechanism, but understanding the molecular interactions and subcellular targeting events that control PLC function requires new insight. We demonstrate that PLC $\beta 3$ mainly exists within the nucleus of T-ALL cells and translocates to the plasma membrane upon stimulation. Therefore, we envision that a pathway contributing to signal transduction from $\mathrm{CD} 3$ to the nucleus may be affected by ORP4L, and our new findings provide insight into points at which this pathway is regulated. In particular, ORP4L enables CD3 signalling to $G \alpha_{q / 11}$. It also facilitates the shift of PLC $\beta 3$ location from the nucleus to the plasma membrane. This promotes assembly of $\mathrm{CD} 3 \varepsilon, G \alpha_{\mathrm{q} / 11}$ and PLC $\beta 3$ into a macromolecular complex to enhance the efficiency, selectivity and specificity of CD3-G protein signal transduction for $\mathrm{Ca}^{2+}$ homeostasis in T-ALL cells.

In normal $\mathrm{T}$-cells subjected to anti-CD3 stimulation, LAT (pp36) is heavily tyrosine phosphorylated and subsequently binds PLC $\gamma 1$ to increase $\mathrm{IP}_{3}$ and intracellular $\mathrm{Ca}^{2+}$ in a G proteinindependent manner ${ }^{44-46}$. This process is required for $\mathrm{CD} 3 \zeta$ chain recruitment to active ZAP70 with a central role in CD3 signaling 47,48 . However, $\mathrm{CD} 3 \zeta$ chain expression in T-ALL cells is defective ${ }^{49}$. Thus, CD3 signalling is swapped to $G \alpha_{q / 11}$ in the presence of ORP4L and sequentially activates $G \alpha_{q / 11}$ and PLC $\beta 3$, which becomes the dominant enzyme for $\mathrm{IP}_{3}$ generation and intracellular $\mathrm{Ca}^{2+}$ homeostasis in T-ALL cells. We conclude that ORP4L in this way supports mitochondrial oxidative phosphorylation for T-ALL cell survival (Fig. 5i).

In agreement with the observed effects of ORP4L on $\mathrm{IP}_{3}$ generation, spontaneous $\left[\mathrm{Ca}^{2+}\right]_{i}$ oscillations in the cytosol and the mitochondria were reduced in ORP4L knockdown cells. Furthermore, ORP4L manipulations were shown to modify the mitochondrial PHD activity, OCR and ATP levels. These observations provide evidence that ORP4L controls ER $\mathrm{Ca}^{2+}$ release by facilitating the catalytic action of PLC $\beta 3$ to sustain PHD activity and ATP production. In contrast to many other types of cancers, T-ALL cells do not appear to over-utilize aerobic glycolysis, also known as the Warburg effect ${ }^{24}$, but rely on oxidative phosphorylation for ATP production. The results in our study and those recently reported in chronic lymphocytic leukemia cells ${ }^{38}$ and leukemia stem cells ${ }^{41}$ reveal a defect in 
a

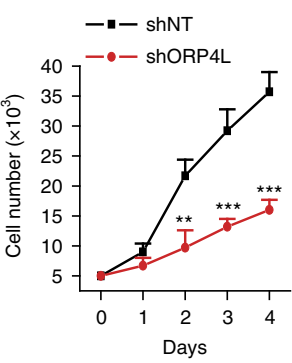

C

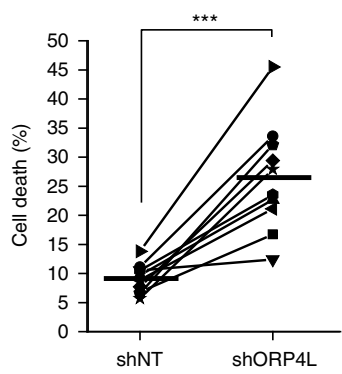

f

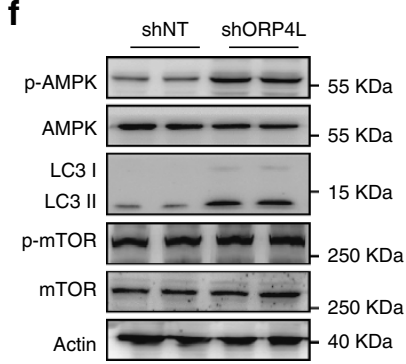

b

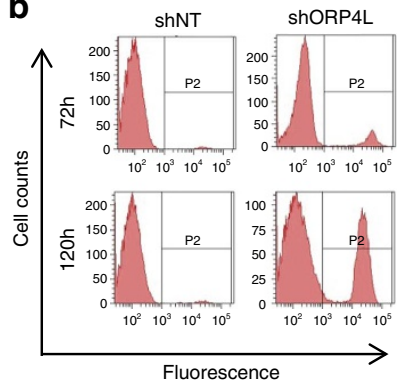

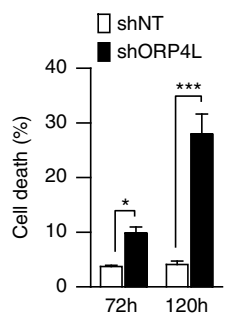

d
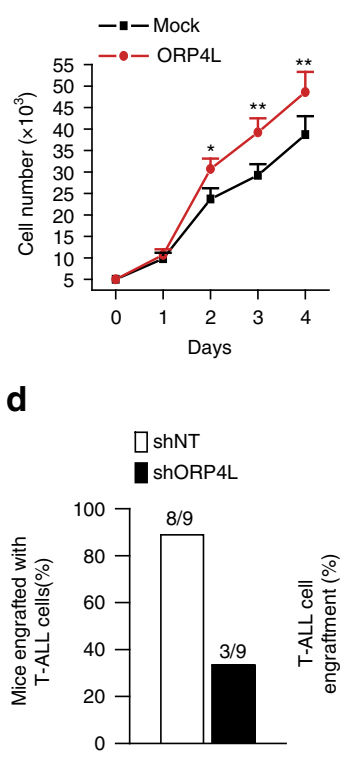$$
\text { - }
$$

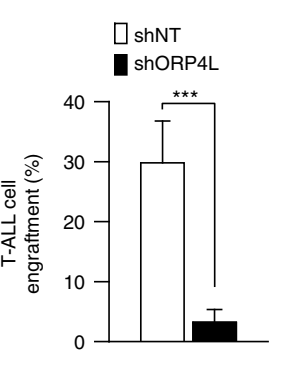

e

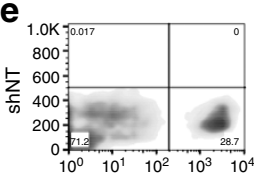

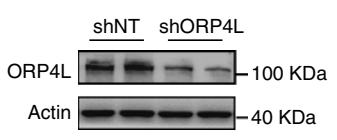

g

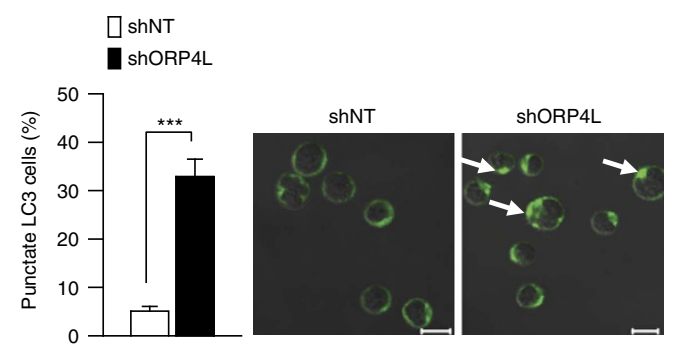

Comp C

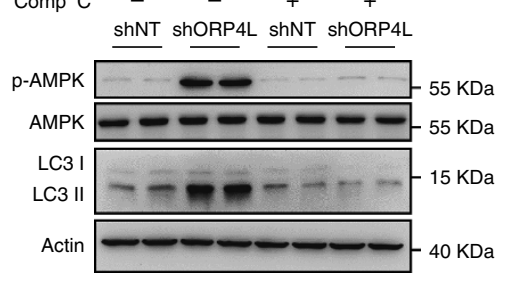

h

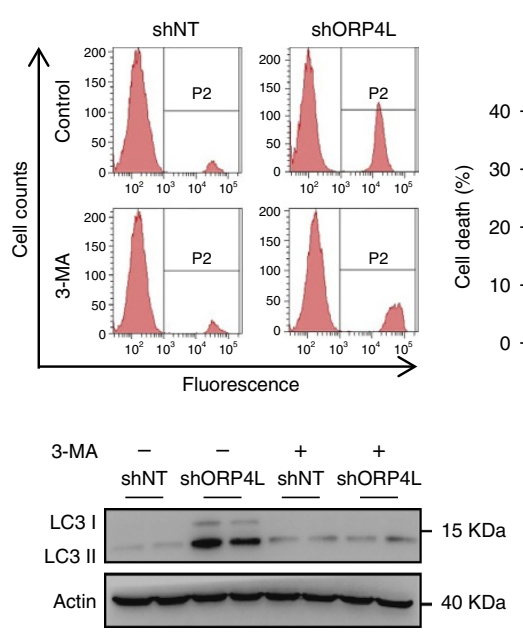

i

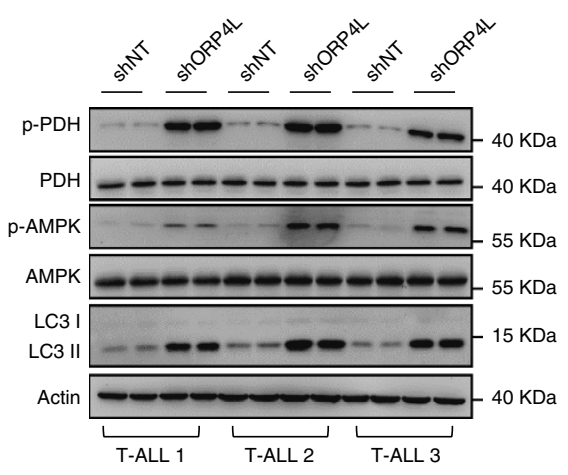

Figure 6 | ORP4L is essential for T-ALL cell survival. (a) Proliferation assay in Jurkat T-cells with ORP4L knockdown (left) or overexpression (right). (b) Cell death analysis in Jurkat T-cells with ORP4L knockdown for 72 and $120 \mathrm{~h}$. (c) Cell death analysis in primary T-ALL cells from 10 specimens with ORP4L knockdown for $120 \mathrm{~h}$. (d) The proportion of mice engrafted with primary T-ALL cells (left), and engrafted primary T-ALL cells as a percentage of the total white blood cells (right), ( $n=9$ of shNT mice, $n=3$ of shORP4L mice). (e) Flow cytometric analysis of engrafted primary T-ALL cells in the blood of NOD/SCID mice with representative dot plots are shown. Western blot indicates ORP4L knockdown efficiency of T-ALL cells after infected with lentivirus for $72 \mathrm{~h}$. (f) Western blot analysis of p-AMPK, LC3 and p-mTOR in control and ORP4L knockdown Jurkat T-cells (left). Confocal images of LC3 puncta in control and ORP4L knockdown Jurkat T-cells (middle and right). Arrows show LC3 puncta (200 cells from three experiments with 10 random fields/ experiment). Scale bars, $10 \mu \mathrm{m}$. (g) Western blot of p-AMPK and LC3 in control and ORP4L knockdown Jurkat T-cells with or without AMPK inhibitor compound C (comp C, $15 \mu \mathrm{M}, 4 \mathrm{~h}$ ). (h) Cell death analysis in Jurkat T-cells with or without autophagy inhibitor, 3-MA. After infection with shNT or shORP4L lentivirus for $48 \mathrm{~h}$, cells were incubated with or without $5 \mathrm{mM}$ 3-MA for further $72 \mathrm{~h}$, and then used for cell death analysis. The Western blot at the bottom verifies that 3-MA inhibited autophagy formation. (i) Western blot of p-PDH, p-AMPK and LC3 in primary T-ALL cells with ORP4L knockdown. The data represent mean \pm s.d. value from an experiment performed in triplicate. ${ }^{\star} P<0.05,{ }^{\star \star} P<0.01,{ }^{\star \star \star} P<0.001$, Student's $t$ test. 
employing glycolysis. The reasons for this phenotype represent an important avenue of future investigation. Enhanced oxidative phosphorylation induced by reprogramming of $\mathrm{Ca}^{2+}$ homeostasis by ORP4L in T-ALL cells offers a plausible mechanistic explanation for the mode of energy metabolism in these transformed leukemia cells.

In accordance with the role in ATP production, ORP4L acts as a key protein in T-ALL cell survival. ORP4L-depleted cells displayed growth suppression and were sensitized to energy status-dependent autophagic cell death in vitro. Further support for this concept was produced by primary T-ALL cell engraftment in a NOD/SCID model. Reduced engraftment of T-ALL cells with ORP4L knockdown in a NOD/SCID model demonstrated that ORP4L is crucial for T-ALL cell survival in vivo.

In conclusion, our results reveal that selective ORP4L expression in T-ALL cells mediates G protein-dependent signalling and leads to translocation and activation of PLC $\beta 3$ to maintain $\mathrm{Ca}^{2+}$ homeostasis and bioenergetics. ORP4L is thus essential for T-ALL cell survival and could therefore be a viable therapeutic target for T-ALL. Inhibition of its expression/activity by RNAi or small-molecular compounds may serve as a new approach to treat this deadly malignancy.

\begin{abstract}
Methods
Reagents and antibodies. Fura-2-AM, Fluo-4-AM, Rhod-2-AM, Fluo-5N-AM, BODIPY-cholesterol, TRIzol reagent, Alexa Fluor-488 goat anti-mouse IgG (Catalogue No. A-11001, diluted 1:200 for immunofluorescence), Alexa Fluor-543 goat anti-rabbit IgG (Catalogue No. A-11035, diluted 1:200 for immunofluorescence) and Alexa Fluor-647 donkey anti-goat IgG (Catalogue No. A-21447, diluted 1:200 for immunofluorescence) were purchased from Invitrogen (Carlsbad, CA, USA). Hoechst 33342, U73122, XeC, thapsigargin and JC-1 were from Sigma-Aldrich (St Louis, MO, USA). Compounds C, Ru360 and ionomycin were from Merck Millipore (Billerica, MA, USA). Kaempferol and BAPTA-AM were purchased from Selleckchem. LEAF purified human anti-CD3 (clone HIT3a Catalogue No. 300314), Alexa Fluor-647 anti-human CD45 (Catalogue No. 304056, diluted 1:20 for flow cytometric) and anti-H2A (Catalogue No. 613301, diluted 1:500 for immunoblotting) were obtained from BioLegend (San Diego, CA, USA). Anti-PLC $\beta 3$ (Catalogue No. sc-133231, diluted 1:200 for immunoblotting and 1:50 for immunofluorescence), anti-PLC $\gamma 1$ (Catalogue No. sc-7290, diluted 1:200 for immunoblotting), anti- $\mathrm{G} \alpha_{\mathrm{q} / 11}$ (Catalogue No. sc-392, diluted 1:200 for immunoblotting and 1:50 for immunofluorescence), anti-pan-cadherin (Catalogue No. sc-1499, diluted 1:200 for immunoblotting and 1:50 for immunofluorescence) and anti-PTEN (Catalogue No. sc-7974, diluted 1:200 for immunoblotting) were from Santa Cruz (Santa Cruz, CA, USA). Anti-p-PDH (Catalogue No. NB110-93479, diluted 1:1,000 for immunoblotting) was obtained from Novus (St Louis, MO, USA); Anti-p-PLCß3 (Catalogue No. 2481, diluted 1:1,000 for immunoblotting and 1:100 for immunofluorescence), anti-PDH (Catalogue No. 2784, diluted 1:1,000 for immunoblotting), anti-mTOR1(Catalogue No. 2972, diluted 1:1,000 for immunoblotting), anti-p-mTOR1 (Ser2448) (Catalogue No. 2971, diluted 1:1,000 for immunoblotting), anti-Notch-1 (Catalogue No. 3268, diluted 1:1,000 for immunoblotting), anti-AMPK (Catalogue No. 2603, diluted 1:1,000 for immunoblotting) and anti-p-AMPK (Thr172) (Catalogue No. 2535, diluted 1:1,000 for immunoblotting) from Cell Signaling (Beverly, MA, USA), and anti-actin (Catalogue No. 60008-1, diluted 1:3,000 for immunoblotting) was from Proteintech Group (Chicago, IL). Anti-ORP4L (Catalogue No. HAP021514, diluted 1:1,000 for immunoblotting and 1:200 for immunofluorescence) from SigmaAldrich was used for all of the experiments except for ORP4L-associated proteome analysis. Cross-linking reagent DSP was purchased from Thermo Scientific.
\end{abstract}

cDNA constructs. Human full length ORP4L, ORP4M, ORP4S, PLC $\beta 3$ and PLC $\gamma 1$ cDNAs were amplified by PCR amplification from HeLa cell cDNA, subcloned into pcDNA4HisMaxC (Invitrogen) vector. The PH domain and FFAT motif deletion fragments were amplified by PCR from ORP4L cDNA. Primers used for these constructs can be found in Supplementary Table 4. The construct were verified by sequencing.

\footnotetext{
Human leukocyte specimens and cell lines. This study was approved by the institutional ethics committee of Jinan University and was performed in accordance with the Declaration of Helsinki. Fresh leukocytes were isolated from peripheral blood of healthy human donors and T-ALL patients after obtaining written informed consent. The clinical information and application of total of 18 T-ALL samples are provided in Supplementary Table 1. Naive CD3 ${ }^{+}$T-cells were isolated using an Enhanced Human T Cell Recovery Column Kit (Cedarlane, Burligton, ON, Canada) according to the manufacturer's instructions and
}

maintained in RPMI 1640 containing 10\% FBS. Jurkat, Molt-4, CEM and MT-4 cells were purchased from American Type Culture Collection and maintained in RPMI 1640 containing $10 \% \mathrm{FBS}, 100 \mathrm{U} \mathrm{ml}^{-1}$ penicillin, and $100 \mu \mathrm{g} \mathrm{ml}^{-1}$ streptomycin at $37^{\circ} \mathrm{C}$ in a humidified incubator with $5 \% \mathrm{CO}_{2}$. All of cell lines were authenticated by Promega short-tandem repeat analysis and tested for mycoplasma contamination before experiments.

Gene transfer. For ORP4L, PLC $\beta 3$ and PLC $\gamma 1$ knockdown and ORP4L overexpression, we used high-titer lentiviral shRNA- and CDNA-expressing vectors prepared by Shanghai GenePharma Co (Shanghai, China). The shRNA sequence can be found in Supplementary Table 3. For lentivirus infection, cells were cultured overnight in media. The following day, $1 \times 10^{6}$ cells were resuspended in $100 \mu \mathrm{l}$ medium with lentivirus (multiplicity of infection $(\mathrm{MOI})=100$ ) and $5 \mu \mathrm{g} \mathrm{ml}^{-1}$ polybrene in 24-well culture plate. Infections were carried out for $6 \mathrm{~h}$ at $37^{\circ} \mathrm{C}, 5 \%$ $\mathrm{CO}_{2}$. After the end of infection, $400 \mu \mathrm{l}$ medium was added. Knockdown or overexpression was verified by western blotting after 4 and 2 days infection, respectively. For other genes transfer, cells were electroporated using an 4D-Nucleofector System (Lonza, Basel, Switzerland) according to the manufacturer's instructions. The transfection efficiency can reach up to $80 \%$ and verified by western blotting.

Extracellular flux assays and ATP generation measurement. Oxygen consumption was assessed using MitoXpress-Xtra-HS (Cayman Chemical, Ann Arbor, MI, USA), a porphyrin-based phosphorescent oxygen-sensitive probe. Before assay, cells were transferred into fresh culture medium containing $1 \%$ FBS. Overall, $10 \mu \mathrm{l}$ of probe was added and the cells were equilibrated at $37^{\circ} \mathrm{C}$. The assay was read using a Microplate Reader (Synergy 4 Hybrid, BioTek, Winooski, VT, USA). The maximal rate of oxygen consumption is proportional to the change in probe fluorescence during the linear phase of the assay. The lactic acid levels and ATP levels were determined by glycolysis cell-based assay kit (Cayman Chemical) and ATP Bioluminescence Assay Kit CLS II (Roche, Basel, Switzerland) according to the manufacturer's instructions.

Mitochondrial and cytosolic ATP measurements. Mitochondrial and cytosolic ATP levels were measured using a luciferase probes PcDNA3-COX8-luc and PcDNA3lucLL/V, respectively. After $24 \mathrm{~h}$ of transfection, cells were rinsed in PBS, and resuspended in $90 \mu \mathrm{l}$ of a $25 \mathrm{mM}$ Tricine, $150 \mathrm{mM} \mathrm{NaCl}$ buffer, $\mathrm{pH}$ 7.4. Overall, $10 \mu \mathrm{l}$ of $20 \mathrm{mM}$ beetle luciferin (Promega, Madison, WI, USA; final concentration $2 \mathrm{mM}$ ) was added to the cell suspension and light emission measured in Microplate Reader (Synergy 4 Hybrid, BioTek). To normalize for the variability of luciferase expression in transfected cells, the relative luminescence values in each cell compartment were expressed as a ratio to the 'total potential luminescence' measured on equal aliquots of the same lysed cells with a luciferase assay kit according to the manufacturer's protocol (Promega) in the presence of excess ATP (0.5 mM final concentration).

Measurement of ROS levels. Endogenous ROS levels of normal T-cells and primary T-ALL cells were detected by labelling cells for $20 \mathrm{~min}$ at $37^{\circ} \mathrm{C}$ with $10 \mu \mathrm{M}$ redox-sensitive probe DCFH-DA (Life Technologies). After washing three times with PBS, cells were analyzed using flow cytometer (FACSAriaTM, BD).

Quantitative real-time PCR and RT-PCR. Total RNA was isolated with TRIzol reagent according to the manufacturer's instructions. RNA samples were reverse transcribed using random hexamer primers in the presence of RNase inhibitor (Takara Bio). qRT-PCR was performed with SYBR Premex EX Taq (Takara Bio) using the 7,300 Sequence Detection System (Applied Biosystems, Foster City, CA USA). A relative quantification analysis was performed using the $\Delta \Delta \mathrm{Ct}$ method, with actin as endogenous reference. Relative gene expression is presented as the ratio of target gene to reference. Primer sequences used were as follows: ORP4L (sense $5^{\prime}$-CCCTTCACTAAGGCCGCATC- ${ }^{\prime}$, anti-sense $5^{\prime}$-GAACCCCAAGAG GAGTCTTCG-3'); actin (sense $5^{\prime}$-GGCATCCTCACCCTGAAGTA- ${ }^{\prime}$, anti-sense $5^{\prime}$-AGGTGTGGTGCCAGATTTTC- ${ }^{\prime}$ ). For RT-PCR, PCR primer sets were designed to amplify specific ORP4 isoforms: ORP4L, CGTTAAAGCCCCTGCC TCTTCTGC and GTGTTCATCACGCGGACAGCCTTG; ORP4M, GAAGC GCCTTGGCATGAACCGTAG and GTGTTCATCACGCGGACAGCCTTG; ORP4S, TGGTGTCCTGTGCCATTGTTAAAC and TTGGATGTGATGCGGA AGAGGG. PCR products were separated by $1.5 \%$ agarose gel electrophoresis and visualized with ethidium bromide.

Analysis of the ORP4L-associated proteome. To obtain enough ORP4L antibody, rabbit antibody against human ORP4L were produced by immunizing New Zeal- and White rabbits with recombined protein carrying amino acid 382-485 of human ORP4L (NCBI Reference Sequence: NP_110385.1). Overall, $5 \mathrm{mg}$ of this antibody and control IgG were coupled in $\mathrm{CNBr}$ activated sepharose. Total cell lysates from Jurkat T-cells stimulated with $10 \mu \mathrm{g} \mathrm{ml}^{-1}$ anti-CD3 for $5 \mathrm{~min}$ were immunoprecipitated with antibody-coupled sepharose. The ORP4L and its interacting proteins were eluted and subjected to SDS-PAGE followed by in-gel tryptic digestion and mass spectrometric identification as described previously ${ }^{50}$. 
Co-immunoprecipitation and immunodepletion. For co-immunoprecipitation assays, Jurkat T-cells were stimulated with $10 \mu \mathrm{g} \mathrm{ml}^{-1}$ of anti-CD3, and cell lysates were immunoprecipitated with antibodies as indicated. For immunodepletion assays, cell lysates were precipitated with anti-ORP4L antibody (Sigma-Aldrich), and supernatants were collected for co-immunoprecipitation with anti-G $\alpha_{\mathrm{q} / 11}$.

Immunofluorescence microscopy. Cells seeded onto coverslips were stimulated with anti-CD3 for the time indicated and fixed with $4 \%$ paraformaldehyde for $30 \mathrm{~min}$ at room temperature, followed by permeabilization with $0.1 \%$ Triton X-100 for $5 \mathrm{~min}$, and blocked with $10 \%$ FBS for $30 \mathrm{~min}$ at room temperature. Cells were then incubated with primary antibodies in $5 \% \mathrm{FBS}$ at $4{ }^{\circ} \mathrm{C}$ overnight. After washing three times (10 min each) with PBS, cells were incubated for 30 min with secondary antibody conjugated with fluorescence at $37^{\circ} \mathrm{C}$. The specimens were analyzed using a Zeiss (Oberkochen, Germany) LSM 510 Meta laser scanning confocal microscope system.

Determination of phospholipase C activity. Phospholipase C activity was analyzed by using the EnzChekR Direct Phospholipase C Assay Kit (Molecular Probes, Eugene, OR, USA) according to the manufacturer's instructions.

Plasma membrane preparations. Cell pellets were thawed and resuspended in 20 volumes of $20 \mathrm{mM}$ sodium phosphate buffer, $\mathrm{pH} 7.4$, and were homogenized twice for $30 \mathrm{~s}$ at high speed using a Tissuemizer. Homogenates were centrifuged at $200 \mathrm{~g}$ for $15 \mathrm{~min}$ at $4{ }^{\circ} \mathrm{C}$. The supernatant was removed and reserved on ice. This procedure was repeated twice and the pooled supernatants were then centrifuged at $40,000 \mathrm{~g}$ for $45 \mathrm{~min}$ at $4^{\circ} \mathrm{C}$. Membranes were suspended at $5 \mathrm{mg}$ protein $\mathrm{ml}^{-1}$ and were stored at $-80^{\circ} \mathrm{C}$

Anti-CD3 mediated ${ }^{35}$ S] GTP $\gamma$ S binding assay. Membrane proteins $(40 \mu \mathrm{g})$ were diluted in a final volume of $250 \mu \mathrm{l}$ assay buffer composed of $50 \mathrm{mM}$ Tris $\mathrm{pH}$ 7.4, $100 \mathrm{mM} \mathrm{NaCl}, 0.2 \mathrm{mM}$ EGTA, $3 \mathrm{mM} \mathrm{MgCl} 2,1 \mathrm{mM}$ DTT, $50 \mu \mathrm{M}$ GDP, $0.5 \mathrm{nM}\left[{ }^{35} \mathrm{~S}\right] \mathrm{GTP} \gamma \mathrm{S}$ and $10 \mu \mathrm{g} \mathrm{ml}^{-1}$ of anti-CD3 antibody. Following an incubation period of $120 \mathrm{~min}$ at a temperature of $25^{\circ} \mathrm{C}$ while shaking at 1,000 r.p.m., the reaction was terminated by rapid filtration through Whatman GF/B filters, followed by six washes with $1 \mathrm{ml}$ of ice-cold washing buffer $(50 \mathrm{mM}$ Tris $\mathrm{pH}$ 7.4, $100 \mathrm{mM} \mathrm{NaCl}, 0.2 \mathrm{mM}$ EGTA, $3 \mathrm{mM} \mathrm{MgCl} 2$ ). Subsequently, filters were placed in scintillation vials containing $5 \mathrm{ml}$ liquid scintillation cocktail and decays per minute of the filter-bound $\left[{ }^{35} \mathrm{~S}\right] \mathrm{GTP} \gamma \mathrm{S}$ were measured by a Liquid Scintillation Analyzer (TriCarb B2810TR, Perkin Elmer).

Measurement of $\mathbf{I P}_{\mathbf{3}}$ production. $\mathrm{IP}_{3}$ was measured using the HitHunter $\mathrm{IP}_{3}$ Fluorescence Polarization Assay Kits (DiscoverRx Tech, Fremont, CA, USA). Briefly, $2 \times 10^{4}$ cells in black 384-well plates (Greiner, Germany) were treated with anti-CD3 for the designated times, and the cellular reaction was terminated by adding $0.2 \mathrm{~N}$ perchloric acid. The plate was shaken at 650 r.p.m. for $15 \mathrm{~min}$. The $\mathrm{IP}_{3}$ tracer was subsequently added to each well, and the $\mathrm{IP}_{3}$ binding protein was added to the plate. The polarized fluorescence from the $\mathrm{IP}_{3}$ tracer was read on a Microplate Reader (Synergy 4 Hybrid, BioTek, ). The $\mathrm{IP}_{3}$ concentration was calculated from the $\mathrm{IP}_{3}$ standard curve.

Calcium fluorometry. Cells $\left(1 \times 10^{6}\right.$ cells $\left.\mathrm{ml}^{-1}\right)$ were incubated with $1 \mu \mathrm{M}$ Fura-2-AM for $30 \mathrm{~min}$ at $37^{\circ} \mathrm{C}$ in extracellular calcium buffer (ECB, $130 \mathrm{mM} \mathrm{NaCl}$, $5 \mathrm{mM} \mathrm{KCl}, 1.5 \mathrm{mM} \mathrm{CaCl}_{2}, 1 \mathrm{mM} \mathrm{MgCl} 2,25 \mathrm{mM}$ Hepes, $\mathrm{pH} 7.5,1 \mathrm{mg} \mathrm{ml}^{-1} \mathrm{BSA}$, and $5 \mathrm{mM}$ glucose) in dark, after which they were collected and resuspended in ECB for an additional incubation at $25^{\circ} \mathrm{C}$ for $30 \mathrm{~min}$ to permit dye de-esterification. Cells were then collected and resuspended to $2 \times 10^{6} \mathrm{cells} \mathrm{ml}^{-1}$ in ECB. Cells in $100 \mu \mathrm{ECB}$ were transferred to a 96-well black-wall cell culture plates and fluorescence was continuously recorded at $25^{\circ} \mathrm{C}$ (alternating 340 and $380 \mathrm{~nm}$ excitation, $510 \mathrm{~nm}$ emission) in a Microplate Reader (Synergy 4 Hybrid, BioTek).

$\mathbf{C a}^{2}+$ imaging. Cells $\left(0.5 \times 10^{6}\right.$ cells $\left.\mathrm{ml}^{-1}\right)$ were plated onto a glass-bottomed dishes and incubated with $1 \mu \mathrm{M}$ Fluo-4-AM for $30 \mathrm{~min}$ at $37^{\circ} \mathrm{C}$ for $\left[\mathrm{Ca}^{2+}\right]_{\mathrm{c}}$ or $2 \mu \mathrm{M}$ Rhod-2-AM for $60 \mathrm{~min}$ at $37^{\circ} \mathrm{C}$ for $\left[\mathrm{Ca}^{2+}\right]_{\mathrm{m}}$ in ECB. The buffer was replaced and incubation continued for $20 \mathrm{~min}$ at $37^{\circ} \mathrm{C}$ to permit dye de-esterification. Culture dishes were mounted on the stage of an inverted confocal microscope (Zeiss LSM 510 Meta) equipped with a $40 \times$ oil objective. Calcium measurements were performed in fresh RPMI 1640 complete medium with $10 \%$ FBS without phenol red at $37^{\circ} \mathrm{C}$ with $5 \% \mathrm{CO}_{2}$. Cells were excited with lowintensity 488-nm (for Fluo-4-AM) or 546-nm (for Rhod-2-AM) laser excitation and images were acquired at 2-s intervals under time-lapse mode. Spontaneous cytosolic calcium oscillations were recorded for $20 \mathrm{~min}$. Image data were subsequently analyzed using ImageJ (National Institutes of Health) and were presented as a ratio of $\mathrm{F} / \mathrm{F} 0$ in the final results, where $\mathrm{F} 0$ represents baseline fluorescence intensity in each cell.
Measurements of $\mathrm{Ca}^{2}+$ influx and $\mathrm{ER} \mathrm{Ca}^{2}+$ content. For $\mathrm{Ca}^{2+}$ influx experiments, ECB containing $10 \mathrm{mM}$ EGTA instead of $\mathrm{Ca}^{2+}$ was used. Cells $\left(1 \times 10^{6}\right.$ cells ml $\left.{ }^{-1}\right)$ were incubated with $1 \mu \mathrm{M}$ Fura-2-AM for $30 \mathrm{~min}$ at $37^{\circ} \mathrm{C}$ in ECB in dark, after which they were collected and resuspended in ECB for an additional incubation at $25^{\circ} \mathrm{C}$ for $30 \mathrm{~min}$ to permit dye de-esterification. Cells were stimulated with $10 \mathrm{\mu g} \mathrm{ml}^{-1}$ anti-CD3 antibody, then the medium was replaced by $\mathrm{ECB}$ containing $2 \mathrm{mM} \mathrm{CaCl}_{2}$ to measure $\mathrm{Ca}^{2+}$ influx. For $\mathrm{ER} \mathrm{Ca}^{2+}$ recording, we used the low-affinity $\mathrm{Ca}^{2}+$ indicator Fluo-5N-AM. Following the incubation with $10 \mu \mathrm{M}$ Fluo-5N-AM for $2 \mathrm{~h}$ and de-esterified for $1 \mathrm{~h}$ at $37^{\circ} \mathrm{C}$, cells were permeabilized by saponin $\left(50 \mu \mathrm{g} \mathrm{ml}^{-1}\right)$ for $20 \mathrm{~s}$. Cells were plated onto a glass-bottomed dishes and excited with low-intensity 488 -nm laser excitation and images were acquired at 2-s intervals under time-lapse mode in confocal microscope (Zeiss LSM 510 Meta) equipped with a $40 \times$ oil objective. Image data were subsequently analyzed using ImageJ (National Institutes of Health) and were presented as a ratio of F/F0 in the final results, where $\mathrm{F} 0$ represents baseline fluorescence intensity in each cell. Total $\mathrm{Ca}^{2+}$ concentration was measured in three regions of the cell, the cytosolic, the mitochondrial and the ER. $\mathrm{Ca}^{2+}$ concentration was calculated based on the $K_{\mathrm{d}}$ for Fura- 2 of $220 \mathrm{nM}$, Rhod-2 of $570 \mathrm{nM}$ and Fluo-5N of $90 \mu \mathrm{M}$.

Mitochondrial membrane potential measurement and NADH imaging. Inner mitochondrial membrane potential $(\Delta \psi)$ was assessed with the potential sensitive cationic fluorescent dye JC-1 (Sigma-Aldrich). Overall, $1 / 10$ volume of $20 \mu \mathrm{M} \mathrm{JC}-1$ was added to cultured cells followed by incubation at $37^{\circ} \mathrm{C}$ with $5 \% \mathrm{CO}_{2}$ for $15 \mathrm{~min}$. Cells were washed and resuspended to $2 \times 10^{6} \mathrm{cells} \mathrm{ml}^{-1}$ in ECB, and cellular fluorescence was measured in a Microplate Reader (Synergy 4 Hybrid, BioTek) set at an excitation/emission wavelengths of 525/590 nm (JC-1 aggregates) and 490/530 nm (JC-1 monomer). An aliquot of cells for each sample without staining with JC-1 was measured to determine background fluorescence. JC-1 fluorescence was also visualized using fluorescence microscopy (Nikon Eclipse TE2000-s). Stained cells were collected and resuspended in $10 \mu \mathrm{l}$ complete medium, mounted on a coverslip, and images were acquired from three or more randomly chosen fields with G-2 A cube (Ex: $510-560 \mathrm{~nm}, \mathrm{Em:}>590 \mathrm{~nm}$ ) for JC-1 aggregates (red) first and then with FITC cube (Ex: $465-495 \mathrm{~nm}$, Em: 515-555 nm) for JC-1 monomer (green). Images from aliquots of cells stained without JC-1 were acquired as background signal. Data are expressed as ratio of red/green after subtracting the background.

$\mathrm{NAD}(\mathrm{P}) \mathrm{H}$ autofluorescence was imaged by fluorescence microscopy. All subsequent incubation and wash steps were carried out in ECB. Cells were washed, suspended to $0.5 \times 10^{6} \mathrm{cells} \mathrm{ml}^{-1}$, and $0.25 \mathrm{ml}$ of suspended cells were applied on coverslip dishes $(25-\mathrm{mm})$ for $10 \mathrm{~min}$ at room temperature and images were acquired with DAPI cube (Ex: $340-380 \mathrm{~nm}$, Em: $435-485 \mathrm{~nm}$ ) with $40 \times$ objective for fluorescence microscopy (Nikon Eclipse TE2000-s). Pictures were taken with the same excitation intensity and exposure time. $\mathrm{NAD}(\mathrm{P}) \mathrm{H}$ fluorescence intensity per cell was analyzed with ImageJ (National Institutes of Health).

Cell proliferation and cell death assay. For cell proliferation assay, 5,000 Jurkat T-cells infected with control or shORP4L lentivirus for $24 \mathrm{~h}$ were plated in 96 -well flat bottom plates with RPMI 1640 medium supplemented with $10 \%$ of FBS. After 14 days' culture, cell numbers were evaluated by Cell Counting kit-8 (WST-8 assay, Dojindo, Molecular Technologies, Rockville, MD, USA) following the manufacturer's protocol. Cell number was calculated by standard curve method, and the averages of at least three times independent experiments were presented. Cell death was analyzed by LIVE/DEAD Fixable Dead Cell Stain Kits (Life Technology) according to the manufacturer's instructions. Briefly, cells were washed once with PBS, and then incubated with LIVE/DEAD Fixable Dead Cell Stain in PBS for 30 min at room temperature in the dark. After washing with PBS with $1 \%$ FBS, cells were resuspended in PBS with 1\% FBS and analyzed using flow cytometer (FACSAriaTM, BD).

In vivo animal studies. This study has been conducted in accordance with the ethical standards and according to the Declaration of Helsinki and according to national and international guidelines and has been approved by the institutional ethics committee of Jinan University. Mice were kept under pathogen-free conditions in the Laboratory Animal Center, Sun Yat-sen University. To establish an engraftment model in female NOD/SCID mice, $2 \times 10^{7}$ primary T-ALL cells were infected by shNT and shORP4L lentivirus. After $72 \mathrm{~h}$ infection, cells were resuspended in $200 \mu \mathrm{l}$ PBS and injected via the tail vein of 6-weeks age female animals, randomly. At 2 weeks post-injection, mice were sacrificed, and engraftment was assayed by flow cytometric detection of human CD $45^{+}$T-ALL cells.

Detection of ER-mitochondrial contact sites. For transmission electron microscopy, cells were fixed with $2.5 \%$ glutaraldehyde in $0.1 \mathrm{M}$ sodium cacodylate buffer for $1-2 \mathrm{~h}$, contrasted with $1 \%$ osmium tetroxide, dehydrated through a graded ethanol series, and embedded in plastic. Ultrathin sections were examined with a FEI Tecnai 10 (Hillsboro, OR, USA) transmission electron microscope. For ultra-high resolution fluorescence microscopy, cells were transfected with DsRedMito and GFP-ER for $24 \mathrm{~h}$ before fixation. Fluorescence images were acquired using DeltaVision Elite system (GE Healthcare, Little Chalfont, Buckinghamshire, UK). Co-localization between the ER and mitochondrial markers was quantified by calculating Pearson's correlation coefficient. 
BODIPY-cholesterol labelling and chase. BODIPY-cholesterol was complexed with methyl- $\beta$-cyclodextrin at a molar ratio of sterol/cyclodextrin $1 / 10$, probe sonicated for $3 \times 15 \mathrm{~min}$ on ice and centrifuged at $10,000 \mathrm{~g}$ for $2 \times 30 \mathrm{~min}$. Jurkat T-cells were transfected with DsRed-Mito or DsRed-ER plasmid and cultured for $24 \mathrm{~h}$ before BODIPY-chol labelling. Cells were seeded onto coverslips and incubated in serum-free medium at $37^{\circ} \mathrm{C}$. Then $1 \mathrm{ul} \mathrm{M} \beta \mathrm{CD} / \mathrm{BODIPY}$-chol complex was added as in 1:2,000 dilutions, resulting in a final concentration of $0.185 \mathrm{mM}$ $\mathrm{M} \beta \mathrm{CD}$ and $\sim 1 \mu \mathrm{M}$ BODIPY-chol. After labelling for $10 \mathrm{~min}$ at $37^{\circ} \mathrm{C}$, the cells were washed three times with PBS. The cells were chased and imaged in a $\mathrm{CO}_{2}$-independent medium at $37^{\circ} \mathrm{C}$. Images were taken with LSM 510 Meta laser scanning confocal microscope system. Co-localization of BODIPY-chol and the red organelles marker, as expressed by the Pearson's correlation coefficient was used as a measure of the relative amount of BODIPY-chol in the organelle.

Western blot analysis. Cellular total protein samples were mixed with loading sample buffer, boiled for $10 \mathrm{~min}$, and subjected to SDS-PAGE followed by transfer onto PVDF membranes (Millipore, Life Science). After blocking and incubations of the membranes with primary antibodies and HRP-secondary antibody conjugates (Bio-Rad Laboratories), the blots were developed by enhanced chemiluminescence (Millipore, Life Science). Proteins were quantified by densitometry using ImageJ (National Institutes of Health) and the data normalized using the $\beta$-actin signal. The original uncropped scans of all the western blot results are provided in Supplementary Fig. 13.

Statistics. The data are expressed as mean \pm s.d. All comparisons between groups were made by unpaired two-tailed Student's $t$ test. $P$ values of $<0.05$ were considered statistically significant.

Data availability. The authors declare that all data supporting the findings of this study are available within the article and its Supplementary Materials, or from the corresponding authors upon request.

\section{References}

1. Hanahan, D. \& Weinberg, R. A. Hallmarks of cancer: the next generation. Cell 144, 646-674 (2011).

2. Cheong, H., Lu, C., Lindsten, T. \& Thompson, C. B. Therapeutic targets in cancer cell metabolism and autophagy. Nat. Biotechnol. 30, 671-678 (2012)

3. Vander Heiden, M. G. Targeting cancer metabolism: a therapeutic window opens. Nat. Rev. Drug. Discov. 10, 671-684 (2011).

4. Pui, C. H., Gajjar, A. J., Kane, J. R., Qaddoumi, I. A. \& Pappo, A. S. Challenging issues in pediatric oncology. Nat. Rev. Clin. Oncol. 8, 540-549 (2011).

5. Coustan-Smith, E. et al. Early T-cell precursor leukaemia: a subtype of very high-risk acute lymphoblastic leukaemia. Lancet Oncol. 10, 147-156 (2009).

6. Baughman, J. M. et al. Integrative genomics identifies MCU as an essential component of the mitochondrial calcium uniporter. Nature 476, 341-345 (2011).

7. De Stefani, D., Raffaello, A., Teardo, E., Szabo, I. \& Rizzuto, R. A fortykilodalton protein of the inner membrane is the mitochondrial calcium uniporter. Nature 476, 336-340 (2011).

8. Foskett, J. K. \& Philipson, B. The mitochondrial $\mathrm{Ca}(2+)$ uniporter complex. J. Mol. Cell Cardiol. 78, 3-8 (2015).

9. Cardenas, C. et al. Essential regulation of cell bioenergetics by constitutive InsP3 receptor $\mathrm{Ca} 2$ + transfer to mitochondria. Cell 142, 270-283 (2010).

10. Hajnoczky, G., Robb-Gaspers, L. D., Seitz, M. B. \& Thomas, A. P. Decoding of cytosolic calcium oscillations in the mitochondria. Cell 82, 415-424 (1995).

11. Denton, R. M. \& McCormack, J. G. Ca2 + as a second messenger within mitochondria of the heart and other tissues. Annu. Rev. Physiol. 52, 451-466 (1990).

12. Balaban, R. S. The role of $\mathrm{Ca}(2+)$ signaling in the coordination of mitochondrial ATP production with cardiac work. Biochim. Biophys. Acta. 1787, 1334-1341 (2009)

13. Clapham, D. E. Calcium signaling. Cell 80, 259-268 (1995).

14. Berridge, M. J., Lipp, P. \& Bootman, M. D. The versatility and universality of calcium signalling. Nat. Rev. 1, 11-21 (2000).

15. Fu, G. et al. Phospholipase C $\{$ gamma 1 is essential for $\mathrm{T}$ cell development, activation, and tolerance. J. Exp. Med. 207, 309-318 (2010).

16. Irvin, B. J., Williams, B. L., Nilson, A. E., Maynor, H. O. \& Abraham, R. T. Pleiotropic contributions of phospholipase C-gammal (PLC-gamma1) to T-cell antigen receptor-mediated signaling: reconstitution studies of a PLC-gamma1deficient Jurkat T-cell line. Mol. Cell Biol. 20, 9149-9161 (2000).

17. Wang, C., JeBailey, L. \& Ridgway, N. D. Oxysterol-binding-protein (OSBP)related protein 4 binds 25 -hydroxycholesterol and interacts with vimentin intermediate filaments. Biochem. J. 361, 461-472 (2002).

18. Charman, M., Colbourne, T. R., Pietrangelo, A., Kreplak, L. \& Ridgway, N. D. Oxysterol-binding protein (OSBP)-related protein 4 (ORP4) is essential for cell proliferation and survival. J. Biol. Chem. 289, 15705-15717 (2014)
19. Udagawa, O. et al. Oligo-astheno-teratozoospermia in mice lacking ORP4, a sterol-binding protein in the OSBP-related protein family. Genes Cells 19, 13-27 (2013).

20. Fournier, M. V. et al. Identification of a gene encoding a human oxysterolbinding protein-homologue: a potential general molecular marker for blood dissemination of solid tumors. Cancer Res. 59, 3748-3753 (1999).

21. Henriques Silva, N. et al. HLM/OSBP2 is expressed in chronic myeloid leukemia. Int. J. Mol. Med. 12, 663-666 (2003).

22. Burgett, A. W. et al. Natural products reveal cancer cell dependence on oxysterol-binding proteins. Nat. Chem. Biol. 7, 639-647 (2011).

23. Laszlo, J. Energy metabolism of human leukemic lymphocytes and granulocytes. Blood 30, 151-167 (1967).

24. Vander Heiden, M. G., Cantley, L. C. \& Thompson, C. B. Understanding the Warburg effect: the metabolic requirements of cell proliferation. Science 324, 1029-1033 (2009).

25. Weng, A. P. et al. Activating mutations of NOTCH1 in human T cell acute lymphoblastic leukemia. Science 306, 269-271 (2004).

26. Palomero, T. et al. Mutational loss of PTEN induces resistance to NOTCH1 inhibition in T-cell leukemia. Nat. Med. 13, 1203-1210 (2007).

27. Herranz, D. et al. Metabolic reprogramming induces resistance to antiNOTCH1 therapies in T cell acute lymphoblastic leukemia. Nat. Med. 21, 1182-1189 (2015).

28. Stanners, J., Kabouridis, P. S., McGuire, K. L. \& Tsoukas, C. D. Interaction between $\mathrm{G}$ proteins and tyrosine kinases upon $\mathrm{T}$ cell receptor.CD3-mediated signaling. J. Biol. Chem. 270, 30635-30642 (1995).

29. Dowal, L., Provitera, P. \& Scarlata, S. Stable association between G alpha(q) and phospholipase C beta 1 in living cells. J. Biol. Chem. 281, 23999-24014 (2006)

30. Golebiewska, U. \& Scarlata, S. The effect of membrane domains on the G protein-phospholipase Cbeta signaling pathway. Crit. Rev. Biochem. Mol. Biol. 45, 97-105 (2010)

31. Yue, C. \& Sanborn, B. M. KN-93 inhibition of G protein signaling is independent of the ability of $\mathrm{Ca} 2+/$ calmodulin-dependent protein kinase II to phosphorylate phospholipase Cbeta3 on 537-Ser. Mol. Cell Endocrinol. 175, 149-156 (2001)

32. David-Dufilho, M. et al. Endothelial thrombomodulin induces $\mathrm{Ca} 2+$ signals and nitric oxide synthesis through epidermal growth factor receptor kinase and calmodulin kinase II. J. Biol. Chem. 280, 35999-36006 (2005).

33. Chen, R. et al. Bcl-2 functionally interacts with inositol 1,4,5-trisphosphate receptors to regulate calcium release from the ER in response to inositol 1,4,5-trisphosphate. J. Cell Biol. 166, 193-203 (2004).

34. Csordas, G. et al. Structural and functional features and significance of the physical linkage between ER and mitochondria. J. Cell Biol. 174, 915-921 (2006).

35. Phillips, M. J. \& Voeltz, G. K. Structure and function of ER membrane contact sites with other organelles. Nat. Rev. Mol. Cell Biol. 17, 69-82 (2016).

36. Garcia-Ruiz, C. et al. Mitochondrial cholesterol in health and disease. Histol. Histopathol. 24, 117-132 (2009).

37. Montero, M. et al. Direct activation of the mitochondrial calcium uniporter by natural plant flavonoids. Biochem. J. 384, 19-24 (2004).

38. Jitschin, R. et al. Mitochondrial metabolism contributes to oxidative stress and reveals therapeutic targets in chronic lymphocytic leukemia. Blood 123, 2663-2672 (2014).

39. Robb-Gaspers, L. D. et al. Integrating cytosolic calcium signals into mitochondrial metabolic responses. EMBO J. 17, 4987-5000 (1998).

40. Kimball, S. R. Interaction between the AMP-activated protein kinase and mTOR signaling pathways. Med. Sci. Sports Exerc. 38, 1958-1964 (2006).

41. Lagadinou, E. D. et al. BCL-2 inhibition targets oxidative phosphorylation and selectively eradicates quiescent human leukemia stem cells. Cell Stem Cell 12, 329-341 (2013)

42. Manzoli, L. et al. Phosphoinositide signaling in nuclei of Friend cells: tiazofurin down-regulates phospholipase C beta 1. Cancer Res. 55, 2978-2980 (1995).

43. Martelli, A. M. et al. Phosphoinositide signaling in nuclei of Friend cells: phospholipase C beta down-regulation is related to cell differentiation. Cancer Res. 54, 2536-2540 (1994).

44. Park, D. J., Rho, H. W. \& Rhee, S. G. CD3 stimulation causes phosphorylation of phospholipase $\mathrm{C}$-gamma 1 on serine and tyrosine residues in a human T-cell line. Proc. Natl Acad. Sci. USA 88, 5453-5456 (1991).

45. Kanner, S. B., Deans, J. P. \& Ledbetter, J. A. Regulation of CD3-induced phospholipase C-gamma 1 (PLC gamma 1) tyrosine phosphorylation by CD4 and CD45 receptors. Immunology 75, 441-447 (1992).

46. Brownlie, R. J. \& Zamoyska, R. T cell receptor signalling networks: branched, diversified and bounded. Nat. Rev. Immunol. 13, 257-269 (2013).

47. Deindl, S. et al. Structural basis for the inhibition of tyrosine kinase activity of ZAP-70. Cell 129, 735-746 (2007).

48. Acuto, O., Di Bartolo, V. \& Michel, F. Tailoring T-cell receptor signals by proximal negative feedback mechanisms. Nat. Rev. Immunol. 8, 699-712 (2008). 
49. Torelli, G. F. et al. Defective expression of the T-cell receptor-CD3 zeta chain in T-cell acute lymphoblastic leukaemia. Br. J. Haematol. 120, 201-208 (2003).

50. Wang, T. et al. Proteomic modeling for HIV-1 infected microglia-astrocyte crosstalk. PloS one 3, e2507 (2008).

\section{Acknowledgements}

This work was supported by grants from National Basic Research Program of China (2012CB517502 to D.Y.), from Major Research plan of the National Natural Science Foundation of China (91439122 to D.Y.), from NSFC, China (Grant 30971104 to D.Y.), by the Academy of Finland (Grant 285223 to V.M.O.), the Sigrid Juselius Foundation, the Magnus Ehrnrooth Foundation and the Finnish Foundation for Cardiovascular Research (V.M.O.). We thank Prof. Marina Mattiazzi for kindly providing the mitochondrial and cytosolic ATP probe constructs.

\section{Author contributions}

V.M.O and D.Y. conceived and designed the experiments; W.Z., S.L. and W.T. performed the experiments with the assistance of F.L., B.Z., J.L., G.J. and P.L.; W.Z., S.L., V.M.O. and D.Y. analyzed the data with the assistance of B.X., G.L. and J.L for the clinical sample collection and data analysis; W.Z., V.M.O. and D.Y. wrote the paper with assistance from Q.Y. and P.R.H.

\section{Additional information}

Supplementary Information accompanies this paper at http://www.nature.com/ naturecommunications

Competing financial interests: The authors declare no competing financial interests.

Reprints and permission information is available online at http://npg.nature.com/ reprintsandpermissions/

How to cite this article: Zhong, W. et al. ORP4L is essential for T-cell acute lymphoblastic leukemia cell survival. Nat. Commun. 7:12702 doi: 10.1038/ncomms12702 (2016).

\section{(c) (i)}

This work is licensed under a Creative Commons Attribution 4.0 International License. The images or other third party material in this article are included in the article's Creative Commons license, unless indicated otherwise in the credit line; if the material is not included under the Creative Commons license, users will need to obtain permission from the license holder to reproduce the material. To view a copy of this license, visit http://creativecommons.org/licenses/by/4.0/

(C) The Author(s) 2016 